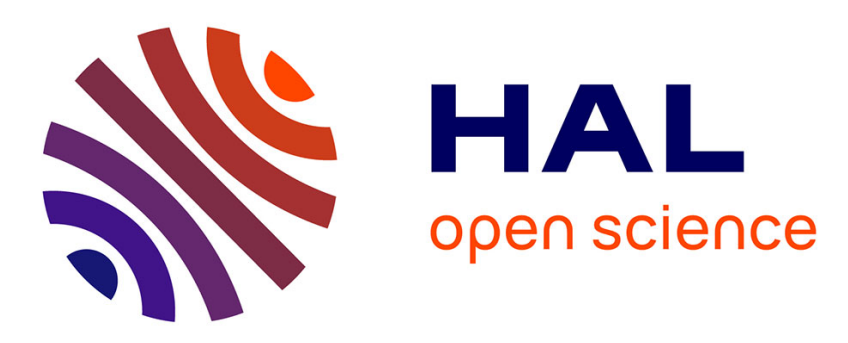

\title{
iCOM formation from radical chemistry: a mechanistic study from cryogenic matrix coupled with IR and EPR spectroscopies
}

\author{
A Gutiérrez-Quintanilla, Y Layssac, T Butscher, S Henkel, Y A Tsegaw, D \\ Grote, W Sander, Fabien Borget, T Chiavassa, Fabrice Duvernay
}

\section{To cite this version:}

A Gutiérrez-Quintanilla, Y Layssac, T Butscher, S Henkel, Y A Tsegaw, et al.. iCOM formation from radical chemistry: a mechanistic study from cryogenic matrix coupled with IR and EPR spectroscopies. Monthly Notices of the Royal Astronomical Society, 2021, 506 (3), pp.3734-3750. 10.1093/mnras/stab1850 . hal-03328863

\section{HAL Id: hal-03328863 https://hal.science/hal-03328863}

Submitted on 30 Aug 2021

HAL is a multi-disciplinary open access archive for the deposit and dissemination of scientific research documents, whether they are published or not. The documents may come from teaching and research institutions in France or abroad, or from public or private research centers.
L'archive ouverte pluridisciplinaire HAL, est destinée au dépôt et à la diffusion de documents scientifiques de niveau recherche, publiés ou non, émanant des établissements d'enseignement et de recherche français ou étrangers, des laboratoires publics ou privés. 


\title{
iCOM formation from radical chemistry: a mechanistic study from cryogenic matrix coupled with IR and EPR spectroscopies.
}

\author{
A. Gutiérrez-Quintanilla, ${ }^{1}$ Y. Layssac, ${ }^{1}$ T. Butscher, ${ }^{1}$ S. Henkel, ${ }^{2}$ Y.A. Tsegaw, ${ }^{2}$ D. Grote, ${ }^{2}$ \\ W. Sander, ${ }^{2}$ F. Borget, ${ }^{1}$ T. Chiavassa, ${ }^{1}$ and F. Duvernay ${ }^{1 \star}$ \\ ${ }^{1}$ Aix Marseille Univ, CNRS, PIIM, Marseille, France \\ ${ }^{2}$ Lehrstuhl für Organische Chemie II, Ruhr-Universität Bochum, 44780 Bochum, Germany
}

28 June 2021

\begin{abstract}
Interstellar complex organic molecules (iCOMs) have been identified in different interstellar environments including star forming regions as well as cold dense molecular clouds. Laboratory studies show that iCOMs can be formed either in gas-phase or in the solid state, on icy grains, from "non-energetic" (atom-addition/abstraction) or energetic (UV-photon, particle bombardments) processes. In this contribution, using a new experimental approach mixing matrix isolation technique, mass spectrometry, and infrared and EPR spectroscopies, we want to investigate the COM formation at $35 \mathrm{~K}$ from a complex mixture of ground state radicals trying to draw a general reaction scheme. We photolyse $(121 \mathrm{~nm}) \mathrm{CH}_{3} \mathrm{OH}$ diluted in $\mathrm{Ar}$ at low temperature (below 15 $\mathrm{K})$ to generate $\mathrm{H}^{\circ} \mathrm{CO}, \mathrm{HO}{ }^{\circ} \mathrm{CO},{ }^{\circ} \mathrm{CH}_{2} \mathrm{OH}, \mathrm{CH}_{3} \mathrm{O}{ }^{\circ},{ }^{\circ} \mathrm{OH}$, and ${ }^{\circ} \mathrm{CH}_{3}$ radicals and "free" $\mathrm{H}$-atoms within the matrix. Radicals have been identified using infrared and EPR spectroscopies. With the disappearance of the Ar matrix (at $35 \mathrm{~K}$ ), these unstable species are then free to react, forming new species in a solid film. Some recombination products have been detected using infrared spectroscopy and mass spectrometry in the solid film after Ar removal, namely methyl formate $\left(\mathrm{CH}_{3} \mathrm{OCHO}\right)$, glycolaldehyde ( $\mathrm{HOCH} \mathrm{CHO}_{2} \mathrm{CHO}$ ), ethylene glycol $\left(\mathrm{HOCH}_{2} \mathrm{CH}_{2} \mathrm{OH}\right)$, glyoxal (CHOCHO), ethanol $\left(\mathrm{CH}_{3} \mathrm{CH}_{2} \mathrm{OH}\right)$, formic acid $(\mathrm{HCOOH})$, dimethyl ether $\left(\mathrm{CH}_{3} \mathrm{OCH}_{3}\right)$, methoxymethanol $\left(\mathrm{CH}_{3} \mathrm{OCH}_{2} \mathrm{OH}\right)$ and $\mathrm{CH}_{4} \mathrm{O}_{2}$ isomers (methanediol and/or methyl hydroperoxide). The detected molecules are fully consistent with the radicals detected and strongly support the solid state scenario of iCOM formation in interstellar ices based on radical-radical recombination. We then discuss astrophysical implications of the radical pathways on the observed gas-phase iCOMs.
\end{abstract}

Key words: Astrochemistry - molecular processes - methods: laboratory: solid state - techniques: spectroscopic - ISM: evolution

\section{INTRODUCTION}

Astrophysical observations have been performed towards different regions of the Interstellar Medium (hereafter ISM). Most of the detected molecules are simple molecules such as $\mathrm{H}_{2} \mathrm{O}, \mathrm{CO}$ and $\mathrm{NH}_{3}$ (Woods et al. 2013) but some of them are more complex. Those with more than six atoms are approximately a third of the total amount of detected interstellar molecules (McGuire 2018). They are usually called interstellar Complex Organic Molecules (hereafter iCOMs) and hold a particular interest since their formation conditions in the ISM are very different from the conditions on Earth. The combination of a very low temperature (10 to $100 \mathrm{~K})$ and very low gas density $\left(<10^{5} \mathrm{~cm}^{-3}\right.$ depending on the region Tielens (2005)) in the ISM prevents the usual reactive pathways to occur since the energetic barriers are too high to be crossed. To date, around 40 iCOMs have been observed such as glycolaldehyde ( $\left.\mathrm{GA}, \mathrm{HOCH}_{2} \mathrm{CHO}\right)$, ethylene glycol (EG, $\mathrm{HOCH}_{2} \mathrm{CH}_{2} \mathrm{OH}$ ), methyl formate (MF, $\mathrm{CH}_{3} \mathrm{OCHO}$ ), formic acid $(\mathrm{FA}, \mathrm{HCOOH})$, or dimethyl ether $\left(\mathrm{DME}, \mathrm{CH}_{3} \mathrm{OCH}_{3}\right)$ to

\footnotetext{
^ E-mail: fabrice.duvernay@univ-amu.fr
}

name only the most famous oxygen bearing iCOMs (Zuckerman et al. 1971; Snyder et al. 1974; Brown et al. 1975; Hollis et al. 2000, 2002). Even thought the presence of iCOMS has been known for decades (Rubin et al. 1971; Brown et al. 1975; Hollis et al. 2000; Remijan et al. 2005; Beltrán et al. 2008), their formation mechanisms are not fully understood and are highly debated.

Since their discovery in the early 1970s, many theoretical and experimental studies were carried out to understand their formation mechanisms in the conditions of the ISM. Most of these studies were first oriented towards gas-phase reactivity (Horn et al. 2004). So far, even sophisticated models of exclusive gas phase reactions are not able to reproduce the molecular abundances of COMs observed in the ISM (Herbst \& Van Dishoeck 2009; Laas et al. 2011; Bergantini et al. 2018). However, recent works claim that some gas-phase reactions have been overlooked in the past, explaining the simulation failures. Evidence is mounting that neutral gas-phase chemistry might play an important role and new reaction pathways are implemented in astrophysical models that now better reproduce iCOM abundances (Skouteris et al. 2017, 2018). Despite this, it is currently accepted (or assumed) that iCOMs are mostly synthetised on the interstellar grain 
surfaces via radical chemistry at low temperature (Garrod \& Herbst 2006; Bennett \& Kaiser 2007b; Woods et al. 2012; Butscher et al. 2015; Fedoseev et al. 2015; Chuang et al. 2016, 2017). However, experimental and theoretical works have recently challenged this way of thinking. Radical-radical recombination does not always form complex molecules (Enrique-Romero et al. 2016; Butscher et al. 2017). For instance, the dimerization of formyl $\mathrm{H}^{\circ} \mathrm{CO}$ radical not only forms glyoxal (CHOCHO) but also $\mathrm{CO}$ and formaldehyde (Butscher et al. 2017). The main reasons are that radical-radical recombination competes with $\mathrm{H}$-abstraction reactions and that radicals are not always oriented in the suitable way for the reaction when trapped in water ice environments (Enrique-Romero et al. 2016, 2020). iCOM formation on interstellar ices based on radical chemistry also suffers the lack of experimental data (activation barriers, diffusion barriers, etc) in condensed phase. Indeed, only few experiments that study individual association reactions between radicals have been undertaken mostly due to the difficulty to detect radicals within the ice analogues (Butscher et al. 2015, 2017, 2019).

Obviously, radicals are not easy to study in solid environments even at low temperature - due to their high reactivity and to their low abundances. To make their observation easier and to monitor the reaction processes, cryogenic matrix-isolation technique can be applied. This method was used in several experiments to analyze hydroxymethyl $\left({ }^{\circ} \mathrm{CH}_{2} \mathrm{OH}\right)$ radical from methanol photolysis or $\mathrm{H}^{\circ} \mathrm{CO}$ radical from hydrogenation of CO (Milligan \& Jacox 1969; Jacox \& Milligan 1973). This technique is able to trap and isolate the radicals from one another, which increase their stability and consequently their lifetime, allowing to probe them with steady-state spectroscopic techniques. However, after matrix vanishing (at $35 \mathrm{~K}$ for Ar matrix), radicals can diffuse and recombine to form a solid film made of COMs (Butscher et al. 2015, 2017, 2019). It is obvious that these matrix experiments do not tend to mimic the interstellar conditions but to identify the radical intermediates and reaction channels.

On the other hand, due to the fact that the identification of radical intermediates is not always straightforward when using IR spectroscopy, even in cryogenic matrices, other techniques have to be considered. Among them Electronic Paramagnetic Resonance (EPR) spectroscopy, used in the present approach, has two main advantages. First, as it detects only paramagnetic species, only radicals will be observed in our samples. So, there are no contributions from other non radical species, making the analysis easier. Secondly, EPR is quite sensitive. This sensitivity solves one problem observed in the infrared spectra: the low band strengths of some radical species make more difficult their detection. Besides, it allows performing shorter photolysis expositions to observe the formed radicals from the very first elementary processes. Radicals of astrophysical interest were studied by this technique; Adrian et al. (1962) presented the EPR spectrum of $\mathrm{H}^{\circ} \mathrm{CO}$ radical and its deuterated form $\mathrm{D}^{\circ} \mathrm{CO}$ in solid carbon monoxide from 4.2 K to $30 \mathrm{~K}$. Zhitnikov \& Dmitriev (2002) identified radicals in astro-relevant environments formed from hydrogenation of $\mathrm{CO}$ or $\mathrm{CH}_{4}$ ices. There are also some known applications of EPR spectroscopy to the photochemical study of complex organic molecules in solid phase or trapped in solid glasses or cryogenic matrices and submitted to $\gamma$ (Mao \& Kevan 1974), X-rays (Toriyama \& Iwasaki 1979; Yamada et al. 1999; Saenko \& Feldman 2016) or VUV photolysis (Watanabe et al. 2007; Tsegaw et al. 2016). However, its application is not widespread in the astrochemical community, and we believe that its potential in this field has not been fully explored neither.

As shown by several experimental studies, the type of COMs formed in solid ices depends on their temperature, on the kind of radiation sources used to form the radicals but also on the ice com- position, especially the nature of radical precursors. Among them, methanol $\left(\mathrm{CH}_{3} \mathrm{OH}\right)$ one of the most abundant COMs in the ISM, is considered as an important radical precursor (Herbst \& van Dishoeck 2009). There are several studies addressing the radiation-induced chemistry of this molecule in different kinds of astrochemically relevant ices, and under exposure to different radiation sources such as electrons (Bennett et al. 2007; Boamah et al. 2014; Maity et al. 2015), protons (Modica \& Palumbo 2010; Occhiogrosso et al. 2011), X-rays (Chen et al. 2013; Saenko \& Feldman 2016), and VUV light (Öberg et al. 2009; Henderson \& Gudipati 2015; Abou Mrad et al. 2016; Paardekooper et al. 2016; Schneider et al. 2019), simulating different ISM environments. The vast amount of COMs that can be formed from radiation-induced transformations of this single molecule and its mixtures with other zeroth-precursors (e.g. $\mathrm{H}_{2} \mathrm{O}, \mathrm{CO}$ or $\mathrm{CH}_{4}$ ) has been well characterized by spectroscopic and chromatographic techniques (Bennett \& Kaiser 2007a,b; Öberg et al. 2009; Maity et al. 2015; Abou Mrad et al. 2016). The formation of most of these complex molecules from methanol rich ices has been explained for a long time by radical-radical recombination reactions (Bennett \& Kaiser 2007b; Öberg et al. 2009; Maity et al. 2015; Abou Mrad et al. 2016). Indeed, different radicals can be produced from methanol irradiated samples, but not all of them are easily observed, or not observed at all, with the most common used techniques in this field i.e. FT-IR and mass spectrometry. For instance, formyl $\left(\mathrm{H}^{*} \mathrm{CO}\right)$ - and possibly hydroxymethyl $\left({ }^{\circ} \mathrm{CH}_{2} \mathrm{OH}\right)$ - is the only radical species observed using infrared spectroscopy in interstellar ice analogues containing methanol exposed to radiation sources (Bennett \& Kaiser 2007a,b; Öberg et al. 2009). Thus, despite the general consensus about the possible role of radical-radical recombination reactions in iCOM formation, there is no complete experimental evidence linking the presence of different radicals produced during the photolysis stage and their final recombination products (i.e. COMs). It is this gap we want to fill.

In this work, we present new results on the VUV photolysis of methanol trapped in argon matrix. We first focus on the identification of radical species using infrared and EPR spectroscopies namely $\mathrm{H}^{\circ} \mathrm{CO}, \mathrm{HO}{ }^{\circ} \mathrm{CO},{ }^{\circ} \mathrm{CH}_{2} \mathrm{OH}, \mathrm{CH}_{3} \mathrm{O}^{\circ},{ }^{\circ} \mathrm{OH}$ and ${ }^{\circ} \mathrm{CH}_{3}$. We then study the radical recombination reactions taking place after rare gas desorption by identifying the newly formed COMs using infrared spectroscopy and mass spectrometry. The goal of the present paper is the analysis of the relation between different families of radicals produced inside the matrix and the observed stable products (COMs) after matrix desorption. This is made possible thanks to the experimental methodology (rare gas matrices, FT-IR, EPR, QMS-TPD) that allows - for the first time - the radical and COM detection in the same experimental conditions. We present possible formation mechanisms of some iCOMs in solid state. Their astrophysical implications are finally discussed in the last part of this paper.

\section{EXPERIMENTAL AND THEORETICAL DETAILS}

A standard procedure for the infrared matrix isolation and Temperature Programmed Desorption (TPD) experiments was used. Details about the experimental setup, including VUV photolysis, were already presented in a previous work, see reference Butscher et al. (2015). Briefly, the copper sample holder is placed in a chamber under high vacuum conditions (from $10^{-8} \mathrm{mbar}$ at room temperature to $10^{-9}$ mbar at $15 \mathrm{~K}$ ). The system temperature is controlled by means of an ARS Cryo $4 \mathrm{~K}$ cold head combined with a resistive heater and a Lakeshore 336 temperature controller. Temperature changes are performed with a $4 \mathrm{~K} \mathrm{~min}^{-1}$ ramp. The chosen precur- 
sor, methanol $\left({ }^{12} \mathrm{C} 99.95 \%\right.$ purity, and ${ }^{13} \mathrm{C} 99 \%$ isotopic purity, Sigma Aldrich) was trapped inside an argon matrix (99.999 \%, Air Liquide) at $14 \mathrm{~K}$ ( $4 \mathrm{~K}$ in the case of EPR). Experiments were initially carried out with different deposition conditions, i.e. 50 and 100 mbar of deposited sample and with guest/host mixtures of 0.5:1000, $1: 1000$, and 2:1000. We have finally chosen the 1:1000 guest/host mixture ratio as it presents the best compromise between methanol concentration, the amount of methanol dimers in the samples, and the quality of the spectra. The chemical composition of our sample is analysed by infrared spectroscopy, using a Bruker Vertex 70 Fourier transform infrared (FTIR) spectrometer with a MCT detector in the reflection-absorption mode. There is an angle of $18^{\circ}$ between the normal of the sample holder and the infrared beam. Resolution of the spectra is set at $0.5 \mathrm{~cm}^{-1}$ and each spectrum is averaged over $20\left({ }^{12} \mathrm{C}\right)-40\left({ }^{13} \mathrm{C}\right)$ cumulated scans. 100 scans are recorded for the background with the same resolution.

Column densities $(N)$ in molec $\mathrm{cm}^{-2}$ are measured using $N=$ $\frac{\int_{v_{1}}^{v_{2}} 2.3 A b s(v) \mathrm{d} v}{2 \cos (18) A}$, where $\int_{v_{1}}^{v_{2}} A b s(v) \mathrm{d} v$ is the integrated absorbance $\left(\mathrm{cm}^{-1}\right)$ of an infrared band whose boundaries are $v_{1}$ and $v_{2}$ and $A$ is the intrinsic band strength $\left(\mathrm{cm} \mathrm{molec}^{-1}\right)$.

In these experiments different radicals are produced from VUV photolysis of methanol trapped in argon matrix. The VUV photons (Lyman- $\alpha$ photons) are generated from a microwave-discharged hydrogen-flow lamp (MDHL) with a running $\mathrm{H}_{2}$ pressure around 0.25 mbar. The emitted VUV flux is transmitted from the plasma chamber to the vacuum chamber through an $\mathrm{MgF}_{2}$ window and was measured to be $4.1 \pm 0.9 \times 10^{13}$ photons $\mathrm{cm}^{-2} \mathrm{~s}^{-1}$ using the known $\mathrm{H}_{2} \mathrm{CO}$ photodissociation cross section. We monitored using infrared spectroscopy the radical production during the photolysis to guarantee an efficient radical production. The photolysis was performed during 3 hours in a discontinuous way to record infrared spectra at different photolysis times (see Fig. 2). In a typical experiment, radical-radical recombination products are obtained by warming the matrix until $35 \mathrm{~K}$ and its subsequent evaporation at higher temperatures. After the argon sublimation is completed samples are warmed up to $300 \mathrm{~K}$ and the desorbing molecules are analysed using a Hiden analytical HAL 201 quadrupole mass spectrometer (QMS) with a $70 \mathrm{eV}$ electron impact source. The source is placed near the sample holder so that pumping losses are minimized.

Very similar experimental conditions were used for the EPR (Xband) measurements conducted in collaboration with the Lehrstuhl für Organische Chemie II team in Ruhr-Universität Bochum. In matrix EPR-spectroscopy experiments small amounts of $\mathrm{CH}_{3} \mathrm{OH}$ was deposited along with argon on a sample holder cooled to $4 \mathrm{~K}$. In this case the experiment was performed using two different sample holders: the sample was deposited onto (i) a sapphire support or (ii) a copper rod attached to the cryostat. In both cases the results were quite similar, although annealing experiments were only developed on the copper rod support. EPR experiments were performed using a Bruker Elexsys E500 EPR spectrometer with an ER077R magnet and ER047 XG-T microwave bridge. More details about this experimental setup and the measurement procedure can be found in Tsegaw et al. (2016). After deposition the matrix is irradiated during 1 hour by a MDHL to produce the radicals. The sample holder is subsequently positioned into the microwave cavity inside a static magnetic field. The magnetic field is scanned while the frequency of the microwave irradiation is fixed ( $\mathrm{X}$ band), and resonance and thus absorption of microwave energy is observed if the energy splitting due to the magnetic field matches the microwave energy. However, the EPR spectrum is usually represented in derivative mode, where the y-axis represents the derivative of the absorption EPR signal w.r.t. the magnetic field intensity. The g-factor of a radical signal depends on the angular momentum of the unpaired electron of the radical which is different to that of a free electron. An anisotropic angular momentum leads to three different g-values (gxx, gyy, gzz), and additional splitting of the signals, e.g. in many oxygen-centered radicals. Hyperfine interaction and g-factors have characteristic values for the investigated radicals. A hydrogen atom in an EPR spectrometer has a defined isotropic g-value and splits into two signals due to the interaction of the electron $(S=1 / 2)$ with the nucleus $(S=1 / 2)$ (Walton 2012). The Easyspin software was used to simulate the EPR spectrum and compare it with the experimental one (Stoll \& Schweiger 2006). In the conditions of our experiments a random orientation of the different radicals is expected and the rigid limit is fulfilled. Taking into account this conditions the pepper module (to simulate cw-EPR spectra for powders) was utilized.

DFT calculations were performed using the Gaussian16 program package (Frisch et al. 2016). The B3-LYP functional (Becke 1993) was used with the def2-TZVP basis set (Weigend \& Ahlrichs 2005). Frequency calculations were performed after a first optimization step at the UB3LYP/def2tzv level of theory for methanol and photolysis products (radicals, etc). A "very tight" convergence criteria and "ultrafine" integration grid were used during optimization. No scaling factor correction for frequencies was implemented. No symmetry was forced and input geometries were always built with no symmetry.

\section{RESULTS}

\subsection{Deposited sample}

Different $\mathrm{CH}_{3} \mathrm{OH}$ :Ar mixtures were deposited on the copper surface at $14 \mathrm{~K}$ and analyzed with FT-IR spectroscopy. Table 1 displays the identified absorption bands of methanol trapped in Ar matrix. An example of the spectra of deposited $\left({ }^{12} \mathrm{C}\right.$ and $\left.{ }^{13} \mathrm{C}\right)$ samples can be seen in Fig. 1. Assignments for both isotopologues $\left({ }^{12} \mathrm{C}\right.$ and $\left.{ }^{13} \mathrm{C}\right)$ were done based on the work of Barnes \& Hallam (1970). Under our experimental conditions, methanol is mainly present as isolated monomers and is characterized by several bands. The most intense band of the ${ }^{12} \mathrm{C}$ monomer is at $1033.7 \mathrm{~cm}^{-1}$ related to the $\mathrm{C}-\mathrm{O}$ stretching mode, but other modes are also detectable such as $\mathrm{C}-\mathrm{H}$ stretching at 3004.7 and $2847.6 \mathrm{~cm}^{-1}, \mathrm{C}-\mathrm{H}$ bending at 1474.1 and $1466.0 \mathrm{~cm}^{-1}$, and $\mathrm{OH}$ group stretching and bending modes at 3666 and $1333.0 \mathrm{~cm}^{-1}$ respectively. Same modes are easily observed for the ${ }^{13} \mathrm{C}$ isotopologue. While small, the presence of dimer bands is observed for $\mathrm{CH}_{3} \mathrm{OH}: \mathrm{Ar}=1: 1000$ mixture ratio. We reported all the bands in Table 1.

\subsection{Photolysis process: FT-IR results}

After deposition, photolysis of the sample was performed at Lyman$\alpha$ wavelength (121.6 nm) during three hours (accumulated time). Under such conditions, methanol was consumed up to $30 \%$ of the deposited amount (Fig. 2). The photolysis time was set to efficiently generate the different radical species (Fig. 2) as well as to get an important methanol destruction. Photolysis times longer than one hour guarantee a steady-state for most radicals and some photoproducts (see the assignment below) as seen in Fig. 2. We also performed the photolysis at lower VUV flux. The same species are produced at similar fluence (i.e. longer photolysis time).

Important changes are observed in the IR spectrum after photolysis, showing that the chemical composition of our matrix sample is 


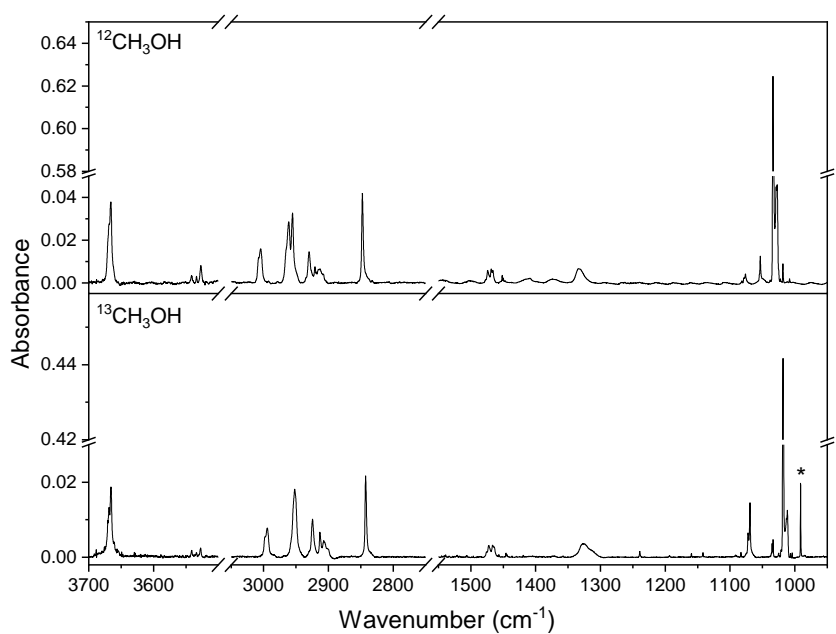

Figure 1. Top panel: FT-IR spectrum of ${ }^{12} \mathrm{CH}_{3} \mathrm{OH}: \mathrm{Ar}=1: 1000$ deposited at $14 \mathrm{~K}$. Lower panel: FT-IR spectrum of ${ }^{13} \mathrm{CH}_{3} \mathrm{OH}: \mathrm{Ar}=1: 1000$ deposited at 14 $\mathrm{K}$. * This band (located at $998 \mathrm{~cm}^{-1}$ ) belongs to the ${ }^{13} \mathrm{CH}_{3}{ }^{18} \mathrm{OH}$ isotopologue $(\sim 3 \%)$

Table 1. Infrared absorption bands of ${ }^{12} \mathrm{CH}_{3} \mathrm{OH}$ and ${ }^{13} \mathrm{CH}_{3} \mathrm{OH}$ in Ar matrix at $14 \mathrm{~K}$, and assignments according to Barnes \& Hallam (1970) and Coussan et al. (1997). Experimental and theoretical (in parenthesis) isotopic shifts $\Delta v$ for the monomer are also shown.

\begin{tabular}{|c|c|c|c|}
\hline \multicolumn{3}{|c|}{ Wavenumbers $\left(\mathrm{cm}^{-1}\right)$} & \multirow[t]{2}{*}{ Assignments } \\
\hline${ }^{12} \mathrm{C}$ & ${ }^{13} \mathrm{C}$ & $\Delta v\left({ }^{12} \mathrm{C}_{-}-{ }^{13} \mathrm{C}\right)$ & \\
\hline 3666.0 & 3665.8 & $\begin{array}{ll}\sim 0 \quad(0) \\
\end{array}$ & $v_{\mathrm{OH}}$ \\
\hline 3541.2 & 3541.5 & - & $v_{\mathrm{OH}}($ dimer $)$ \\
\hline 3533.9 & 3534.0 & - & $v_{\mathrm{OH}}($ dimer $)$ \\
\hline 3527.2 & 3528.0 & - & $v_{\mathrm{OH}}($ dimer $)$ \\
\hline 3004.7 & 2994.8 & $10 \quad(11)$ & $v_{\mathrm{CH}_{3}}(a) \quad \mathrm{A}^{\prime}$ \\
\hline 2961.4 & 2952.0 & $9 \quad(11)$ & $v_{\mathrm{CH}_{3}}(a) \quad \mathrm{A}^{\prime \prime}$ \\
\hline 2955.5 & 2951.7 & $4(6)$ & $2 \delta_{\mathrm{CH}_{3}}(a) \quad \mathrm{A}^{\prime}$ \\
\hline 2929.9 & 2924.4 & $6(5)$ & $2 \delta_{\mathrm{CH}_{3}}(a) \quad \mathrm{A}^{\prime \prime}$ \\
\hline 2920.8 & 2913.3 & - & Combination bands ${ }^{\dagger}$ \\
\hline $2914.0^{b r}$ & 2907.4 & - & Combination bands ${ }^{\dagger}$ \\
\hline 2847.6 & 2842.5 & $5 \quad(3)$ & $v_{\mathrm{CH}_{3}}(s) \quad \mathrm{A}^{\prime}$ \\
\hline 2054.9 & 2022.9 & 32 (35) & $2 v_{\mathrm{CO}} \quad \mathrm{A}^{\prime}$ \\
\hline 1474.1 & 1472.3 & $2(2)$ & $\delta_{\mathrm{CH}_{3}}(a) \mathrm{A}^{\prime}$ \\
\hline 1466.0 & 1465.3 & 1 (2) & $\delta_{\mathrm{CH}_{3}}(a) \mathrm{A}^{\prime \prime}$ \\
\hline 1451.7 & 1445.8 & $6 \quad(7)$ & $\delta_{\mathrm{CH}_{3}}(s) \mathrm{A}^{\prime}$ \\
\hline $1333.0^{b r}$ & 1326.6 & $6 \quad(8)$ & $\delta_{\mathrm{OH}} \quad \mathrm{A}^{\prime}$ \\
\hline 1076.3 & 1069.3 & $7(8)$ & $\rho_{\mathrm{CH}_{3}} \quad \mathrm{~A}^{\prime}$ \\
\hline 1053.4 & 1035.3 & - & $\nu_{\mathrm{C}-\mathrm{O}}($ dimer $)$ \\
\hline 1033.7 & 1018.4 & 15 (15) & $v_{\mathrm{C}-\mathrm{O}} \quad \mathrm{A}^{\prime}$ \\
\hline 1027.5 & 1011.7 & - & $v_{\mathrm{C}-\mathrm{O}}($ dimer $)$ \\
\hline
\end{tabular}

$\nu$ : stretching; $\delta$ : bending; $\rho$ : rocking; $a$ : antisymmetric; $s$ : symmetric $b r$ Broad. ${ }^{\dagger}$ Tentatively assigned.

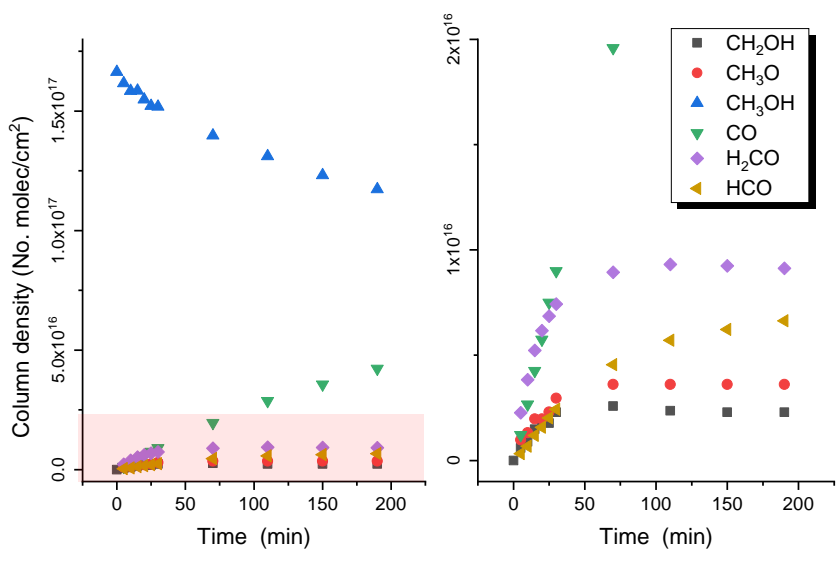

Figure 2. Kinetics of methanol and some photoproducts during VUV photolysis at $14 \mathrm{~K}$. The represented "Time" corresponds to accumulated photolysis times because the process is performed in a discontinuous way. The right panel is a zoom of the red region in the left panel. The bands used to quantify each species are: $1180.1 \mathrm{~cm}^{-1}\left({ }^{\circ} \mathrm{CH}_{2} \mathrm{OH}\right), 1364.1 \mathrm{~cm}^{-1}\left(\mathrm{CH}_{3} \mathrm{O}^{\bullet}\right), 1033.7$ $\mathrm{cm}^{-1}\left(\mathrm{CH}_{3} \mathrm{OH}\right), 2138.2 \mathrm{~cm}^{-1}(\mathrm{CO}), 1743.2 \mathrm{~cm}^{-1}\left(\mathrm{H}_{2} \mathrm{CO}\right)$ and $1863.6 \mathrm{~cm}^{-1}$ $\left(\mathrm{H}^{\circ} \mathrm{CO}\right)$. The integral extension coefficients used to obtain the column densities were taken from Bennett et al. (2007).

modified. To highlight these changes, we made a difference spectrum with spectra obtained before and after VUV photolysis. Thus, newly formed species appear as positive bands while consumed products are displayed as negative bands (see Fig. 3). Contributions of new compounds are listed in Table 2. Characteristic IR signatures of associated and monomeric $\mathrm{CO}$ are detected at 2148.7 and $2138.2 \mathrm{~cm}^{-1}$ respectively. Formaldehyde $\mathrm{H}_{2} \mathrm{CO}$ is also detected with its absorption bands at 2797.2, 1743.2, and $1498.5 \mathrm{~cm}^{-1}$. They correspond to $\mathrm{C}-\mathrm{H}$ stretching mode, $\mathrm{C}=\mathrm{O}$ stretching mode, and $\mathrm{C}-\mathrm{H}$ bending mode respectively. The characteristic $1305.2 \mathrm{~cm}^{-1}$ rocking band of methane $\mathrm{CH}_{4}$ is also observed. These frequencies are all down-shifted with the ${ }^{13} \mathrm{C}$ isotopic change in good agreement with values reported in literature and with theoretical calculations shown in Table 2. Besides the main products, we also report the formation of $\mathrm{CO}_{2}$ in small amount from the band located at $2343 \mathrm{~cm}^{-1}$ and $2280-2273 \mathrm{~cm}^{-1}$ in ${ }^{13} \mathrm{C}$ experiments (Table 2, Fig. 3). It has to be noted that in ${ }^{13} \mathrm{C}$ experiments, the characteristic band of ${ }^{12} \mathrm{CO}_{2}$ is also detected during the photolysis meaning that a part of observed $\mathrm{CO}_{2}$ in the ${ }^{12} \mathrm{C}$ experiment belongs to background deposition.

\subsubsection{Radical formation}

Unstable reactive species were also identified in our samples. According to Jacox \& Milligan (1973), bands detected at 1332.2, 1183.1, and $1047.7 \mathrm{~cm}^{-1}$ can be safely assigned to ${ }^{\circ} \mathrm{CH}_{2} \mathrm{OH}$ radical $\mathrm{C}-\mathrm{H}$ bending, $\mathrm{C}-\mathrm{O}$ stretching, and $\mathrm{HOCH}$ bending modes, respectively. Compared to other species, these bands seem to be quite sensitive to site effects, as we will discuss later in section 3.4. Formyl radical $\mathrm{H}^{\circ} \mathrm{CO}$ is also identified from its infrared absorption at 1863.6 and $1084.9 \mathrm{~cm}^{-1}$, corresponding to $\mathrm{C}=\mathrm{O}$ stretching and $\mathrm{HCO}$ bending modes, in accordance with values reported by Milligan \& Jacox (1969).

Another unstable compound detected in our experiments displays a band at $904 \mathrm{~cm}^{-1}$. It is assigned to a well described ionic complex $\mathrm{Ar}_{2} \mathrm{H}^{+}$that hints the presence of $\mathrm{H}$ radicals trapped inside the matrix. Indeed, according to Kunttu et al. (1992) and Pettersson et al. (1999), VUV photolysis of small hydrides in matrix environment produces $\mathrm{RgHRg}^{+}$ionic complexes. We also searched for the stretching band of 

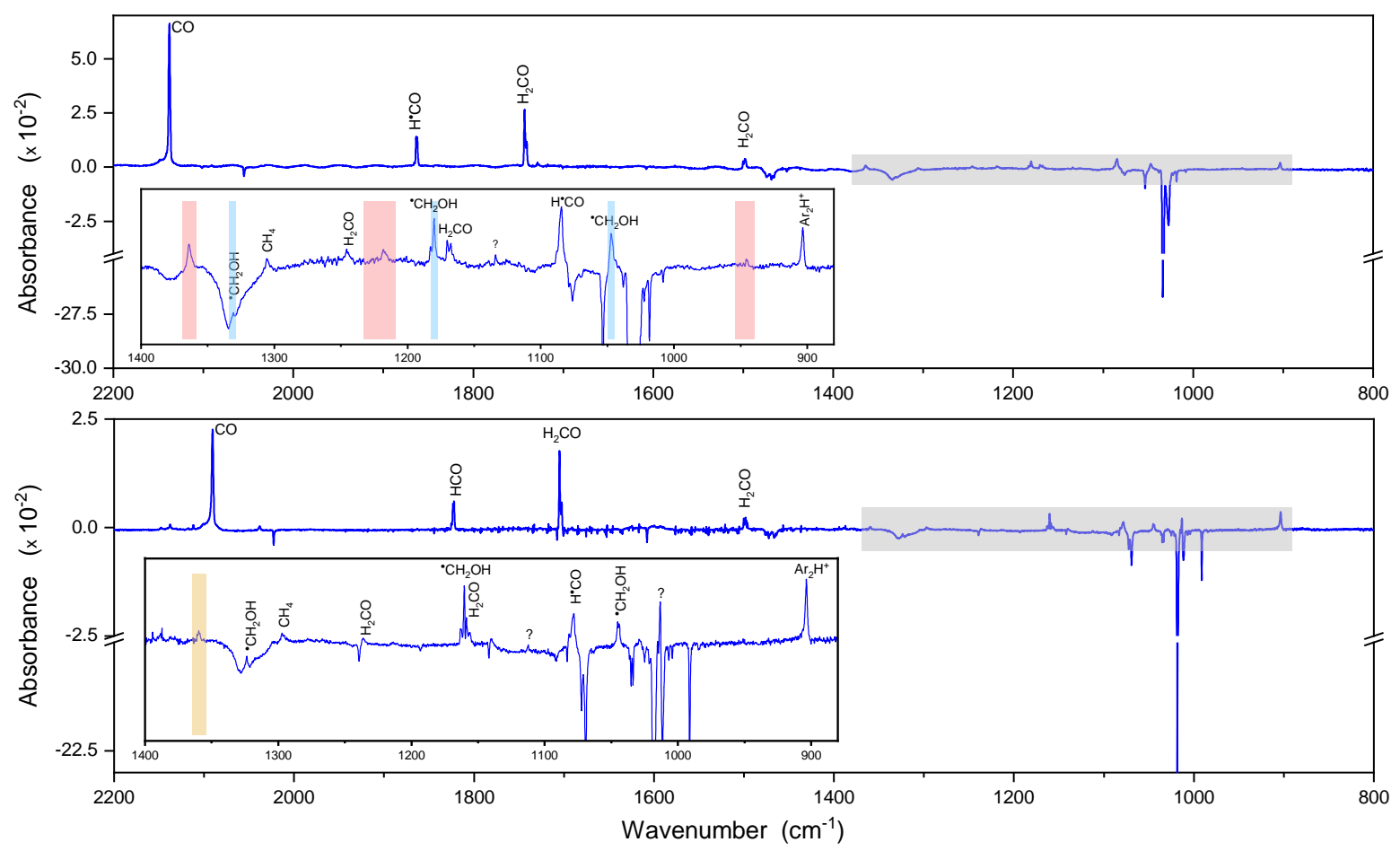

Figure 3. Difference spectrum between spectra obtained after photolysis at $121.6 \mathrm{~nm}$ and just after deposition at $14 \mathrm{~K}$ for ${ }^{12} \mathrm{CH}_{3} \mathrm{OH}$ : Ar sample (top panel) and ${ }^{13} \mathrm{CH}_{3} \mathrm{OH}$ :Ar sample (lower panel). Newly formed products appear as positive bands while methanol bands appear as negative bands. Light blue and red rectangles represent the position and extension of ${ }^{\circ} \mathrm{CH}_{2} \mathrm{OH}$ and $\mathrm{CH}_{3} \mathrm{O}^{\bullet}$ bands in para-hydrogen matrix (Lee et al. 2015) respectively. The orange rectangle corresponds to a tentatively assigned ${ }^{13} \mathrm{CH}_{3} \mathrm{O}{ }^{\circ}$ band $\left(\delta_{\mathrm{CH}}\right)$. ? Unassigned.

the hydroxyl $\left({ }^{\circ} \mathrm{OH}\right)$ radical. We found indeed its characteristic band at $3350.3 \mathrm{~cm}^{-1}$ (Langford et al. 2000; Do et al. 2014). However, we have mainly observed this band when the amount of $\mathrm{CH}_{3} \mathrm{OH}$ was high or there was some presence of water impurities. This implies that we cannot certainly assign this band to ${ }^{\circ} \mathrm{OH}$ radical produced from direct $\mathrm{CH}_{3} \mathrm{OH}$ photolysis, and we just tentatively assigned this band in Table 2 .

A very small signal was detected at $606.6 \mathrm{~cm}^{-1}$ which according to Saenko \& Feldman (2016) can be tentatively assigned to ${ }^{\circ} \mathrm{CH}_{3}$ radical. However, previous studies on this radical have attributed the out of plane mode of this radical to a band around $611-617 \mathrm{~cm}^{-1}$, presenting notable dependence with the temperature (Milligan \& Jacox 1967; Snelson 1970; Jacox 1977). A second less intense band has been found at $603 \mathrm{~cm}^{-1}$. Thus, it is not completely clear whether the observed band in our experiments can be attributed to this radical. Nevertheless we will see later from the EPR results that ${ }^{\circ} \mathrm{CH}_{3}$ radical is observed in the irradiated sample.

\subsection{2 $\mathrm{CH}_{3} \mathrm{O}^{\bullet}$ radical}

Despite several efforts, the infrared signature of the methoxy $\left(\mathrm{CH}_{3} \mathrm{O}^{*}\right)$ radical in argon or rare gas matrices has not been previously reported. Jacox \& Milligan (1973) carried out a similar study to the one described in this paper, i.e. VUV photolysis (hydrogen-discharge lamp and Xe lamp) of $\mathrm{CH}_{3} \mathrm{OH}$ in argon (and nitrogen) matrix. Unlike the ' $\mathrm{CH}_{2} \mathrm{OH}$ radical, no evidence of $\mathrm{CH}_{3} \mathrm{O}$ ' was found in their study. In fact, the use of a discharge source for the production of excited argon and fluorine atoms to react with $\mathrm{CH}_{3} \mathrm{OH}$ increases the amount of ${ }^{\circ} \mathrm{CH}_{2} \mathrm{OH}$, but no trace of $\mathrm{CH}_{3} \mathrm{O}^{\circ}$ was observed (Jacox 1981). On the other hand, several papers were published on the identification of this radical in the gas phase and in molecular jets, mainly through the use of Laser Induced Fluorescence - LIF - (Inoue et al. 1979; Powers et al. 1981; Foster et al. 1988), although other approaches have also been used to characterize its ground and first excited states (for more references see "Introduction" section in Misra et al. (1993)). One of these studies was carried out by Chiang et al. (1989), who characterized with LIF spectroscopy the $\mathrm{CH}_{3} \mathrm{O}^{\bullet}$ radical in argon matrix obtained by laser photodissociation of methyl nitrite $\mathrm{CH}_{3} \mathrm{ONO}$. In a more recent study Lee et al. (2015) photolysed at $355 \mathrm{~nm} \mathrm{CH}_{3} \mathrm{ONO}$ trapped in para-hydrogen matrix. A careful analysis of the FT-IR spectrum supported by high level theoretical calculations allow them to assign different bands of the $\mathrm{CH}_{3} \mathrm{O}^{\circ}$ radical, although a fast conversion to its ${ }^{\circ} \mathrm{CH}_{2} \mathrm{OH}$ isomer was observed. Because of the very low perturbing environment in para-hydrogen matrix, multiplets due to spin-coupling and Jahn-Teller effects in $\mathrm{CH}_{3} \mathrm{O}^{\circ}$ are observed. The regions spanned by such multiplets in the three more intense bands are shown as light red rectangles in Fig. 3. Our experiments in argon matrix show a group of three bands at 1364.4, 1218.2, and 945.7 $\mathrm{cm}^{-1}$. The kinetic study of the $1364.4 \mathrm{~cm}^{-1}$ band (the most intense one) clearly shows a different evolution compared to the previously identified species, but similar to that of ${ }^{\circ} \mathrm{CH}_{2} \mathrm{OH}$ (Fig. 2). The agreement between the three most intense bands assigned by Lee et al. (2015) with those observed in our samples is quite good. We also explored the photolysis of the ${ }^{13} \mathrm{CH}_{3} \mathrm{OH}$ isotopologue. In this case only the most intense band, near $1360 \mathrm{~cm}^{-1}$ is observed (see lower panel in Fig. 3). It has to be mentioned that for this isotopologue the amount of all the produced radical is lower, despite same sample amount and concentration, and very similar percent of consumed methanol ( $\sim 40 \%$ ) during the photolysis. On the other hand, the obtained isotopic shift for this band is in agreement with the estimated theoretical value calculated at B3LYP/def2tvz level of theory (see Table 2). 
Table 2. Infrared absorption bands and assignments of new products formed after ${ }^{12} \mathrm{CH}_{3} \mathrm{OH}$ : Ar and ${ }^{13} \mathrm{CH}_{3} \mathrm{OH}$ :Ar VUV photolysis at $14 \mathrm{~K}$. The isotopic shift is also included along with theoretical values in parenthesis (B3LYP/def2tzv). $t$-HO ${ }^{\circ} \mathrm{CO}$ bands were mainly assigned after annealing step.

\begin{tabular}{|c|c|c|c|}
\hline \multicolumn{3}{|c|}{ Wavenumbers $\left(\mathrm{cm}^{-1}\right)$} & \multirow[b]{2}{*}{ Assignment } \\
\hline${ }^{12} \mathrm{C}$ & ${ }^{13} \mathrm{C}$ & $v\left({ }^{12} \mathrm{C}-{ }^{13} \mathrm{C}\right)$ & \\
\hline \multicolumn{2}{|c|}{$3550.3^{\dagger}$} & & ${ }^{\circ} \mathrm{OH}^{a}$ \\
\hline 2343.0 & $2280-2274$ & $37-31$ & $\mathrm{CO}_{2}{ }^{b}$ \\
\hline 2797.2 & 2792.2 & $5(4)$ & $\mathrm{H}_{2} \mathrm{CO} \quad\left(v_{\mathrm{CH}}\right)^{c}$ \\
\hline 2148.7 & 2101.7 & 46 & $\mathrm{CO}: \mathrm{CH}_{3} \mathrm{OH}\left(v_{\mathrm{CO}}\right)^{d}$ \\
\hline 2138.2 & 2090.4 & 48 & $\mathrm{CO}\left(v_{\mathrm{CO}}\right)^{e}$ \\
\hline 1863.6 & $1822.3^{m}$ & $41 \quad(42)$ & $\mathrm{H}^{*} \mathrm{CO}\left(v_{\mathrm{CO}}\right)^{f}$ \\
\hline 1843.0 & - & (44) & $t-\mathrm{HO}^{*} \mathrm{CO}\left(v_{\mathrm{CO}}\right)^{g}$ \\
\hline 1743.2 & 1705.2 & $38 \quad(40)$ & $\mathrm{H}_{2} \mathrm{CO} \quad\left(v_{\mathrm{CO}}\right)^{c}$ \\
\hline 1498.5 & 1498.4 & $\sim 0 \quad(0)$ & $\mathrm{H}_{2} \mathrm{CO} \quad\left(\delta_{\mathrm{CH}}\right)^{c}$ \\
\hline 1364.1 & 1359.7 & $4(3)$ & $\mathrm{CH}_{3} \mathrm{O}^{\bullet}\left(\delta_{\mathrm{CH}}\right)^{h}$ \\
\hline 1332.2 & 1324.9 & 7 (7) & $\cdot{ }^{\mathrm{CH}_{2}} \mathrm{OH}\left(\delta_{\mathrm{OH}}\right)^{i}$ \\
\hline $1330.7^{\star}$ & $1323.6^{\star}$ & 7 & ${ }^{\cdot} \mathrm{CH}_{2} \mathrm{OH}\left(\delta_{\mathrm{OH}}\right)^{i}$ \\
\hline 1305.5 & 1296.1 & $9(8)$ & $\mathrm{CH}_{4}\left(\delta_{\mathrm{CH}}\right)^{j}$ \\
\hline 1245.9 & 1236.5 & $9(10)$ & $\mathrm{H}_{2} \mathrm{CO} \quad\left(\rho_{\mathrm{CH}}\right)^{c}$ \\
\hline 1218.2 & - & - & $\mathrm{CH}_{3} \mathrm{O}^{\bullet}\left(\rho_{\mathrm{CH}}\right)^{h}$ \\
\hline 1211.0 & - & (4) & $t-\mathrm{HO}^{*} \mathrm{CO}\left(\delta_{\mathrm{HOC}}\right)^{g}$ \\
\hline 1188.3 & 1163.0 & 25 & $\cdot \mathrm{CH}_{2} \mathrm{OH}: \mathrm{CO}\left(v_{\mathrm{CO}}\right)^{k}$ \\
\hline 1183.1 & 1160.4 & $23(20)$ & $\cdot \mathrm{CH}_{2} \mathrm{OH}\left(v_{\mathrm{CO}}\right)^{i}$ \\
\hline $1180.1^{\star}$ & - & - & ${ }^{\cdot} \mathrm{CH}_{2} \mathrm{OH} \quad\left(v_{\mathrm{CO}}\right)^{i}$ \\
\hline 1167.6 & 1156.6 & 11 & $\mathrm{H}_{2} \mathrm{CO}\left(\omega_{\mathrm{CH}}\right)^{c}$ \\
\hline 1084.9 & 1078.5 & $6(7)$ & $\mathrm{H}^{\bullet} \mathrm{CO}\left(\delta_{\mathrm{CHO}}\right)^{f}$ \\
\hline 1047.7 & 1045.2 & $2(2)$ & ${ }^{\cdot} \mathrm{CH}_{2} \mathrm{OH} \quad\left(\delta_{\mathrm{HOCH}}\right)^{i}$ \\
\hline 1039.4 & - & - & $\mathrm{CO}: \mathrm{CH}_{3} \mathrm{OH} \quad\left(\delta_{\mathrm{HOCH}}\right)^{d}$ \\
\hline 945.7 & - & - & $\mathrm{CH}_{3} \mathrm{O}^{\bullet}\left(\rho_{\mathrm{CH}}\right)^{h}$ \\
\hline \multicolumn{2}{|c|}{904} & & $\mathrm{Ar}_{2} \mathrm{H}^{+l}$ \\
\hline
\end{tabular}

Notes: $v$ : stretching; $\delta$ : bending; $\rho$ : rocking; $\omega$ : wagging. ${ }^{\star}$ Band observed after photolysis and disappearing after annealing step in favor of the higher frequency band. ${ }^{m}$ Multiplets. ${ }^{\dagger}$ Tentatively assigned. ${ }^{a}$ Do et al. (2014); Langford et al. (2000); ${ }^{b}$ Irvine et al. (1982); ${ }^{c}$ Khoshkhoo \& Nixon (1973); Saenko \& Feldman (2016); ${ }^{d}$ Diem \& Lee (1979); ${ }^{e}$ Leroi et al. (1964); Abe et al. (1999); ${ }^{f}$ Milligan \& Jacox (1969); ${ }^{g}$ Jacox (1988); ${ }^{h}$ Lee et al. (2015); ${ }^{i}$ Jacox (1981); ${ }^{j}$ Jacox (1979); ${ }^{k}$ Butscher et al. (2015); ${ }^{l}$ Kunttu et al. (1992); Pettersson et al. (1999).

It is worth noting that contrary to para-hydrogen matrix (Lee et al. 2015), no conversion toward ${ }^{\circ} \mathrm{CH}_{2} \mathrm{OH}$ was perceived in argon matrix. This indicates that the $\mathrm{CH}_{3} \mathrm{O}^{\circ}$ radical is stable under the present experimental conditions. Theoretical calculations suggest that $\mathrm{H}$-tunneling assisted $\mathrm{CH}_{3} \mathrm{O}^{\circ} \rightarrow{ }^{\circ} \mathrm{CH}_{2} \mathrm{OH}$ conversion in vacuum at low temperature must be quite slow $\left(\mathrm{k}_{W K B}=4.44 \times 10^{-8} \mathrm{~s}^{-1}\right.$, Wang \& Bowie (2012)). Based on experiments with isotopologues and other theoretical calculations Lee et al. (2015) suggested that the conversion in para-hydrogen matrix is not made via an unimolecular tunneling process but a matrix assisted one. The present results support such a statement.

We have also tried to use $\mathrm{CH}_{3} \mathrm{ONO}$ precursor in our study, as in Chiang et al. (1989) and Lee et al. (2015), in order to see whether

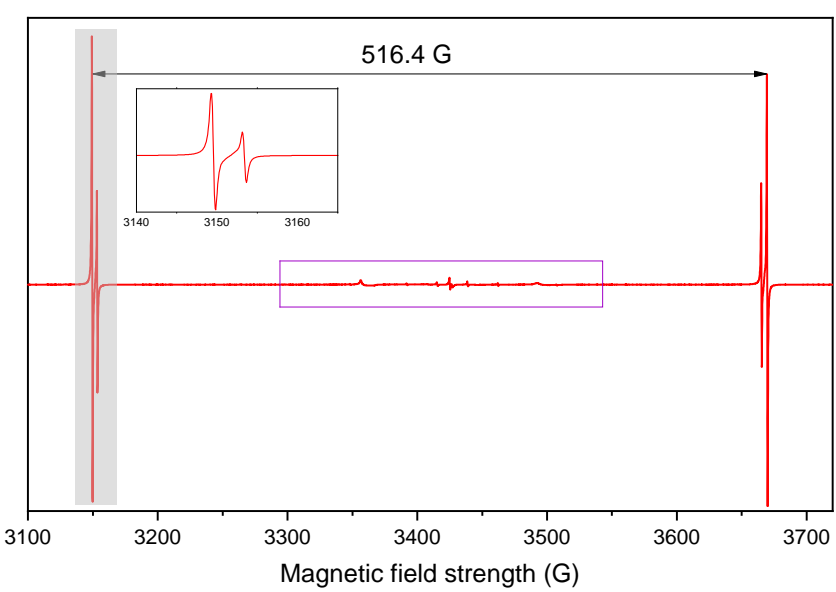

Figure 4. $\mathrm{X}$-Band EPR spectrum at $4 \mathrm{~K}$ of $\mathrm{CH}_{3} \mathrm{OH} / \mathrm{Ar}$ sample after photolysis at $121.6 \mathrm{~nm}$. The inlet correspond to the grey zone. The rectangle in the middle of the spectrum highlights the region where the carbon and oxygen-centered radicals appear.

the production of $\mathrm{CH}_{3} \mathrm{O}^{\circ}$ could be boosted and used as an IR reference for this radical trapped in argon matrix. It should be noted that instead of a monochromatic laser source for photolysis we employed a high pressure $\mathrm{Hg}$ lamp with either pyrex or $\mathrm{MgF}_{2}$ as external windows. In principle, this has the inconvenient that it could promote new photo-fragmentation pathways in the precursor or in the formed secondary products. Nevertheless, no evidence of the previously assigned $\mathrm{CH}_{3} \mathrm{O}^{\circ}$ bands was found in these experiments. The presence of ${ }^{\circ} \mathrm{CH}_{2} \mathrm{OH}$ was not evident neither. We mainly observed different kind of stoichiometric recombination products (e.g. cis and trans $\left.\mathrm{CH}_{2}(\mathrm{NO}) \mathrm{OH}\right)$ and complexes $\left(\mathrm{H}_{2} \mathrm{CO}-\mathrm{HNO}\right)$, and just a very small amount of isolated $\mathrm{HNO}$ and NO. This indicates that there is a strong "cage effect" in argon matrix and consequently the NO fragment cannot escape from the photolysis site as previously reported by Jacox \& Rook (1982).

\subsection{Photolysis process: EPR results}

The presence of radical intermediates can also be revealed by EPR spectroscopy, with the additional advantages of high sensitivity and selectivity for radicals of this technique. We have performed the same kind of experiments previously described but probing the sample with a X-band EPR spectrometer. No signal is detected in the EPR spectrum of the deposited sample, in agreement with the lack of paramagnetic centers at this stage of the experiment. Two features are observed in the EPR spectrum after photolysis (Fig. 4). First, two intense patterns of peaks are detected. The associated g-factors $(\sim 1.9999)$ and the very high hyperfine splitting $(516.4 \mathrm{G})$ are characteristic of free $\mathrm{H}$-atoms, which is in agreement with the previous FT-IR results. The corresponding signature holds two intense coupling patterns and a small third one, which are due to the presence of $\mathrm{H}$-atoms in different interstitial and substitutional sites (Komaguchi et al. 1997).

The top spectrum on Fig. 5 displays the EPR analysis of the sample after photolysis (zoom of the central region of Fig. 4). Due to the presence of multiple radicals, the resulting spectrum is complex. However, as we will see next, we can easily identify signals associated with $\mathrm{H}^{*} \mathrm{CO}$ (external singlets) and ${ }^{\circ} \mathrm{CH}_{3}$ radicals (quartet pattern). For the other species a simulation of the spectrum is thus required for a more accurate identification. We have used the EasySpin 
software which allows an accurate simulation of the EPR spectrum in a multicomponent sample by solving the spin Hamiltonian for each species. An initial set of $g$-factors and $A$-coupling values for each radical was obtained from the literature, and subsequently adjusted to manually fit the experimental spectrum (Siegel et al. 1960; Adrian et al. 1962; Krusic et al. 1971; Tseng \& Chang 1975; Dmitriev 2004; Tsegaw et al. 2016). The optimized set of parameters obtained in our simulations is displayed in Table 3 . The values are quite close to those previously reported. One has to keep in mind that the environment around the radical species modifies the spectrum, thus the simulation parameters (Adrian et al. 1962). The fitting of the simulated spectrum displayed on Fig. 5 shows that four different radical species are mainly responsible for the EPR signature. Two of these radicals were already identified by infrared spectroscopy: ${ }^{\circ} \mathrm{CH}_{2} \mathrm{OH}$ and $\mathrm{H}^{\circ} \mathrm{CO}$. The latter is, along with ${ }^{\circ} \mathrm{CH}_{3}$, the first and most abundant radical observed by EPR after photolysis of the matrix. While ${ }^{\circ} \mathrm{CH}_{3}$ is only tentatively detected in the IR spectrum, $\mathrm{H}^{*} \mathrm{CO}$ is the easiest radical to be detected in our experiments. Its anisotropic structure is combined with a quite large hyperfine coupling, more than 100 $\mathrm{G}$, which is unusual (Adrian et al. 1962). The explanation of this signature lies in a very high spin population on the hydrogen atom due to important weight of a valence bond structure in which this radical is represented by a $\mathrm{CO}$ moiety and an $\mathrm{H}$-atom (Gerson \& Huber 2003). The ${ }^{\circ} \mathrm{CH}_{2} \mathrm{OH}$ radical appears with much less intensity, but it is clearly observed after photolysis. It is a carbon-centered radical presenting a very similar hyperfine coupling with two hydrogen atoms in $\alpha$ position, so its spectrum is expected to be a triplet. However, although weak, a contribution from the coupling with the hydroxyl $(\mathrm{OH})$ hydrogen is also present, contributing to a widening of the signals. The fourth clear observed specie is $t$ - $\mathrm{HO}^{*} \mathrm{CO}$. This is a carbon centered radical with almost negligible coupling with the $\mathrm{H}$-atom, and an anisotropic (axial) $g$-value giving a characteristic signature. It is worth noting that the $g$-values obtained by us are closer to those reported by Tseng \& Chang (1975) in solid phase than those obtained by Sears et al. (1993) in gas phase. Also, an A-coupling value around $2.0 \mathrm{G}$ in the gas phase has been reported by experimental and theoretical works (Sears et al. 1993; Carmichael 1994), which is an order of magnitude higher than the value found in this work $(0.18 \mathrm{G})$. The $c$ is isomer $\left(c-\mathrm{HO}^{\circ} \mathrm{CO}\right)$ presenting a much higher value of $A$-coupling was not observed. This result is consistent with the assignment made for this radical by infrared spectroscopy (see Table 2). Finally, we are also able to detect the presence of the ${ }^{\circ} \mathrm{OH}$ radical that has a non-negligible coupling with the $\mathrm{H}$-atom. Its signal overlaps with ${ }^{\circ} \mathrm{CH}_{2} \mathrm{OH}$ and $\mathrm{H}^{*} \mathrm{OCO}$. In addition, the clear detection of ${ }^{\circ} \mathrm{CH}_{3}$ also implies that the hydroxyl radical should be produced and able to escape from the original cage. In these experiments we were not able to assign the methoxy radical $\mathrm{CH}_{3} \mathrm{O}^{\circ}$. Although it is an isomer of ${ }^{\circ} \mathrm{CH}_{2} \mathrm{OH}$ radical, the single electron being centered on the oxygen atom greatly modifies the spectrum, making easier to differentiate both. As Jacox \& Milligan (1973) noted, the occurrence of a degenerate electronic ground state in $\mathrm{CH}_{3} \mathrm{O}{ }^{\bullet}$ leads to an extreme line broadening, not even being recovered by degeneracy removal induced by the Jahn-Teller distortion of the methyl group, at least in rare-gas matrices. Although the EPR detection of this radical has been proven at low temperature in crystalline methanol (Iwasaki \& Toriyama 1978; Toriyama \& Iwasaki 1979), there is only one recent report published by some of the present authors addressing its detection in rare-gas matrices (Tsegaw et al. 2016). The inclusion of this radical in the present simulated spectrum, with the parameters previously published, does not improve the quality of the fitting. Unfortunately, EPR does not allow neither confirming nor disproving the presence of this radical, already assigned in FT-IR.

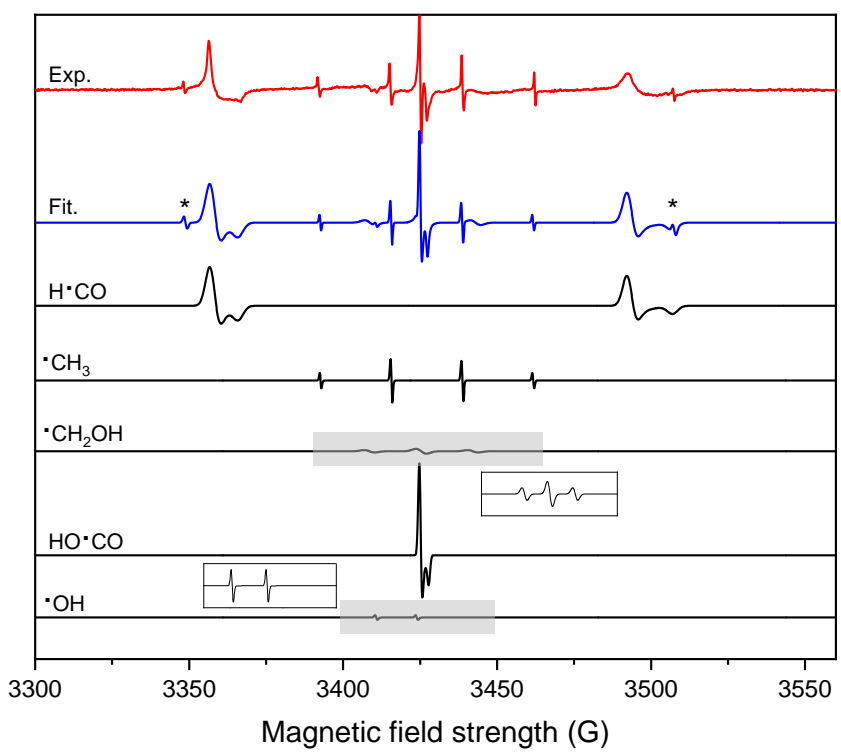

Figure 5. Zoom of EPR spectrum of $\mathrm{CH}_{3} \mathrm{OH} / \mathrm{Ar}$ sample after photolysis at $121.6 \mathrm{~nm}$ at $4 \mathrm{~K}$ compared to simulated spectra of identified radicals. The individual spectra are presented with the weights used in the fitting. All the traces share the same scale. The asterisk denotes the EPR signal from $D$ atoms which were present in the sample as impurity.

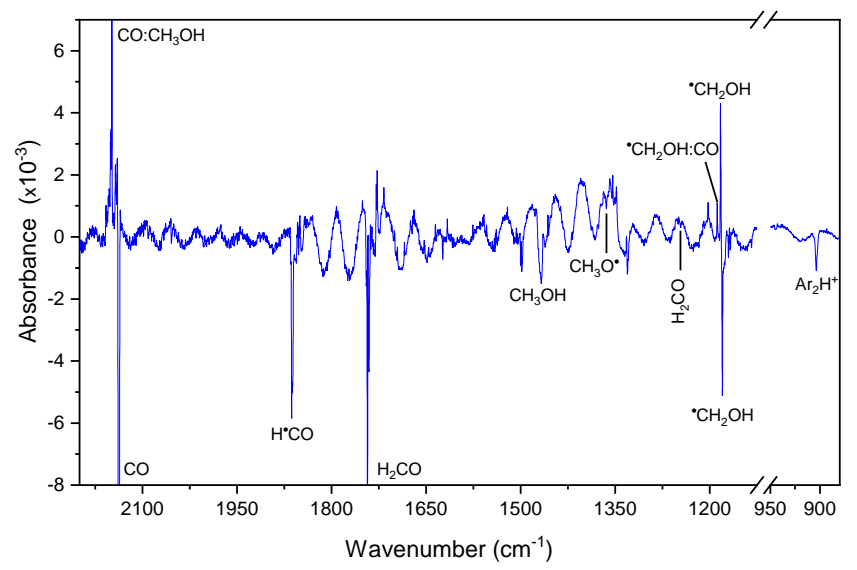

Figure 6. Difference infrared spectrum obtained after subtraction between the spectrum recorded after sample annealing at $30 \mathrm{~K}$ for 10 minutes and subsequent cooling down to $14 \mathrm{~K}$, and the spectrum acquired before the annealing.

We have also performed the same kind of experiments for two other isotopologues: $\mathrm{CD}_{3} \mathrm{OD}$ and $\mathrm{CH}_{3} \mathrm{OD}$ (not shown). The results confirm the conclusions mentioned before, but there is one additional detail worth mentioning. The relative amount of $\mathrm{HO}^{\circ} \mathrm{CO}$ radical (or its deuterated analogues) compared for example to ${ }^{\circ} \mathrm{CH}_{3}$, varies between the different irradiated isotopologues. The highest value is obtained in irradiated $\mathrm{CH}_{3} \mathrm{OH}$ isotopologue, which suggests a formation mechanism resulting from the $\mathrm{CO}_{2}$ hydrogenation process.

\subsection{Annealing step}

Annealing of matrices plays an important role in the study of radical reactivity. The increase of temperature weakens the matrix cages, allowing small species to diffuse through the bulk, especially $\mathrm{CO}$ and $\mathrm{H}$-atoms. $\mathrm{CO}$ diffusion mainly results in the formation of weakly 
Table 3. Parameters used for EPR simulations of detected radicals, and corresponding references from which the initial set of parameters was taken.

\begin{tabular}{ccccc}
\hline \hline Radical & $\mathrm{g}$ & $\mathrm{A}(\mathrm{G})$ & Bandwidth & Ref. \\
\hline $\mathrm{CH}_{3}{ }^{\circ}$ & 2.0007 & 23.02 & 0.07 & $(1)$ \\
\hline \multirow{3}{*}{$\mathrm{H}^{\bullet} \mathrm{CO}$} & 2.001 & $135.32\left(\mathrm{~A}_{x}\right)$ & & \\
& 2.001 & $\begin{array}{c}135.45\left(\mathrm{~A}_{y}\right) \\
1.9945\end{array}$ & 0.38 & $(2)$ \\
& $140.53\left(\mathrm{~A}_{z}\right)$ & & \\
\hline${ }^{\circ} \mathrm{CH}_{2} \mathrm{OH}$ & 2.0015 & $\begin{array}{c}17.13\left(\mathrm{H}_{\alpha}\right) \\
1.8\left(\mathrm{H}_{\mathrm{O}}\right)\end{array}$ & 0.4 & $(3)$ \\
\hline \multirow{5}{*}{$t-\mathrm{HO}{ }^{\circ} \mathrm{CO}$} & 2.002 & & & \\
& 2.002 & 0.18 & 0.08 & $(4)$ \\
\hline${ }^{\circ} \mathrm{OH}$ & 2.0006 & & & \\
\hline \hline
\end{tabular}

(1) Dmitriev (2004), (2) Adrian et al. (1962), (3) Krusic et al. (1971), (4) Tseng \& Chang (1975), (5) Siegel et al. (1960)

bound complexes, and $\mathrm{H}$-atom diffusion in hydrogenation reactions. This increases the chemical diversity in the sample.

Figure 6 displays the difference spectrum between spectra taken before and after annealing at $30 \mathrm{~K}$. The $\mathrm{Ar}_{2} \mathrm{H}^{+}$infrared peak at 903 $\mathrm{cm}^{-1}$ is decreasing which implies that trapped $\mathrm{H}$-atoms are released and will seek a partner to react. This effect was also observed with EPR spectroscopy. Except for the ${ }^{\circ} \mathrm{CH}_{3}$ radical, all the other carboncentered radicals (i.e. $\mathrm{HC}^{\circ} \mathrm{O}$ and ${ }^{\circ} \mathrm{CH}_{2} \mathrm{OH}$ ) plus formaldehyde and methanol are part of the hydrogenation chain reaction of $\mathrm{CO}$, which is known to be an hydrogen scavenger (Butscher et al. 2015). The intermediate species of the $\mathrm{CO}$ hydrogenation chain are formed and consumed by this reaction sequence (reaction 1) during the annealing step.

$\mathrm{CO} \stackrel{H}{\longrightarrow} \mathrm{H}^{\cdot} \mathrm{CO} \stackrel{H}{\longrightarrow} \mathrm{H}_{2} \mathrm{CO} \stackrel{H}{\longrightarrow}{ }^{\circ} \mathrm{CH}_{2} \mathrm{OH} \stackrel{H}{\longrightarrow} \mathrm{CH}_{3} \mathrm{OH}$

Fig. 6 shows that the previous mentioned species appear as negative bands in the difference spectrum, which could imply that they are more consumed than produced during the annealing step. However, during the annealing process, a small part of the matrix evaporates which might contribute to the negative signals. Other processes should also be considered to explain this behavior.

As mentioned before, $\mathrm{CO}$ is known to diffuse through the matrix as the cages are weakened, allowing complexation with other species. The peak at $2138 \mathrm{~cm}^{-1}$ is assigned to CO trapped in the matrix as a monomer. We can observe its disappearance on the spectrum in Fig. 6 while new bands appear close to it. These peaks are related to complexes formed with other species, e.g. $\mathrm{CH}_{3} \mathrm{OH}$, and also radicals such as ${ }^{\circ} \mathrm{CH}_{2} \mathrm{OH}: \mathrm{CO}$ (see Table 2). The complexed species tend to have their vibrational contributions close to the monomeric values. For example, $\mathrm{CH}$ bending mode of ${ }^{\circ} \mathrm{CH}_{2} \mathrm{OH}$ radical is located at $1183.1 \mathrm{~cm}^{-1}$ whereas the ${ }^{-} \mathrm{CH}_{2} \mathrm{OH}: \mathrm{CO}$ complex shows the $\mathrm{CH}$ bending mode of the ${ }^{\circ} \mathrm{CH}_{2} \mathrm{OH}$ part at $1188.3 \mathrm{~cm}^{-1}$, due to the interaction with $\mathrm{CO}$. Furthermore, we can observe "site effects" during the annealing process, which is quite evident for the $v_{\mathrm{CO}}$ mode of the ${ }^{\circ} \mathrm{CH}_{2} \mathrm{OH}$ radical (see Table 2 ).

We observed, using FT-IR spectroscopy, the formation of $\mathrm{HO}^{\circ} \mathrm{CO}$ radical only after the annealing step, although this radical was detected by EPR spectroscopy after photolysis. This indicates that the amount of this radical increases during the annealing step via bimolecular reactions.

Annealing effects can be observed in the EPR spectra as well.

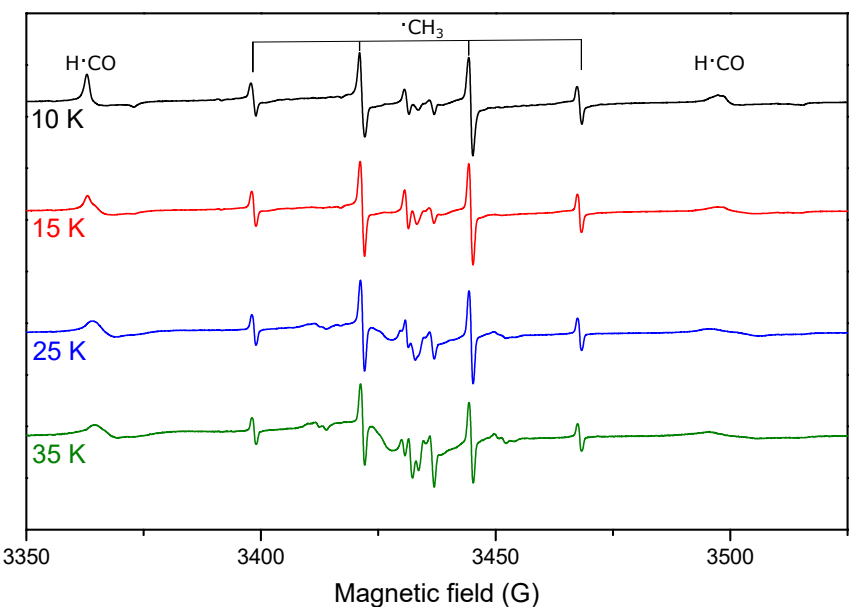

Figure 7. Effect of the annealing step in a $\mathrm{CH}_{3} \mathrm{OH} / \mathrm{Ar}$ sample after photolysis at $121.5 \mathrm{~nm}$. Evolution of the EPR spectrum obtained in a copper rod sample holder. Some of the most important species are label. All the traces share the same scale.

The modification of the environment combined with the consumption and the formation of radical species lead to large changes in the spectra (Fig. 7). For instance, the $\mathrm{H}^{*} \mathrm{CO}$ signature widens and tends to decrease in intensity, while ${ }^{\circ} \mathrm{CH}_{3}$ bands decrease with increasing temperature too. A noticeable amount of radicals survive the annealing step, as can be seen in Fig. 7. In summary, from the EPR and IR spectra it is clear that all the radical species are consumed to some degree, although they are still present in the sample after the annealing step. These radicals will then play the central role in the next stage.

\subsection{Matrix desorption: COM formation}

During the Ar matrix desorption at $35 \mathrm{~K}$, diffusion of ground-state molecules and radicals is increased allowing bimolecular reactions to occur. Once argon evaporation is finished, an amorphous solid film made of stable molecules, including COMs, is obtained (Hama et al. 2017). In this section, the solid film composition is discussed by the means of FT-IR spectroscopy and QMS-TPD analysis. As FT-IR spectroscopy alone is not always enough to characterize a molecule in a complex mixture, none of the COM identification is only based on FT-IR spectroscopy. We additionally used QMS-TPD analysis in ${ }^{12} \mathrm{C}$ and ${ }^{13} \mathrm{C}$ experiments to validate and extend what could have been proposed from FT-IR analysis. In other words, every single molecular assignment is based on several pieces of evidence such as IR band position, desorption temperature, and mass fragmentation pattern. When this degree of characterization could not be reached due to technical limitations or lack of spectroscopic evidence, the molecules were declared as "tentatively assigned". We wish to emphasize that although limited, infrared spectroscopy allows in-situ probing of the radical reactivity at $35 \mathrm{~K}$ in the solid film.

\subsubsection{Solid FT-IR spectrum}

Fig. 8 displays the infrared spectrum at $40 \mathrm{~K}$ of the solid film obtained after rare gas desorption. The absorption bands observed in the solid film $\left({ }^{12} \mathrm{C}\right.$ and ${ }^{13} \mathrm{C}$ samples) are listed in Table 4 along with their vibrational assignments. Several vibrational bands in Fig. 8 are assigned to the remaining methanol in our samples. The bands at $3230,1459,1129$, and $1020 \mathrm{~cm}^{-1}$ are attributed to $\mathrm{O}-\mathrm{H}$ stretching, 
Table 4. Infrared absorption bands and assignments of new products observed in the solid film after ${ }^{12} \mathrm{CH}_{3} \mathrm{OH}$ : $\mathrm{Ar}$ and ${ }^{13} \mathrm{CH}_{3} \mathrm{OH}$ : $\mathrm{Ar}$ VUV photolysis at $14 \mathrm{~K}$ and Ar sublimation at $35 \mathrm{~K}$.

\begin{tabular}{|c|c|c|c|c|}
\hline \multicolumn{2}{|c|}{ Wavenumbers $\left(\mathrm{cm}^{-1}\right)$} & \multirow[t]{2}{*}{ Assignment (mode) } & \multirow[t]{2}{*}{$\mathrm{A}\left(\mathrm{cm} \mathrm{molec}{ }^{-1}\right)$} & \multirow[t]{2}{*}{$\mathrm{N}\left(\right.$ molec $\left.\mathrm{cm}^{-2}\right)$} \\
\hline${ }^{12} \mathrm{C}$ & ${ }^{13} \mathrm{C}$ & & & \\
\hline 2340 & 2280 & $\mathrm{CO}_{2}\left(v_{\mathrm{CO}}\right)$ & $7.610^{-17 a}$ & $6.810^{14}$ \\
\hline 1770 (I) & 1724 & $\mathrm{CH}_{3} \mathrm{COOH}^{\dagger} \quad\left(v_{\mathrm{CO}}\right)$ & $5.210^{-17 e, f}$ & $3.110^{14 \ddagger}$ \\
\hline 1750 (II) & 1707 & $\mathrm{HOCH}_{2} \mathrm{CHO}^{\diamond}\left(v_{\mathrm{CO}}\right)$ & $2.610^{-17 b, c}$ & $1.410^{15}$ \\
\hline 1726 (III) & 1688 & $\mathrm{H}_{2} \mathrm{CO}^{\diamond} \quad\left(v_{\mathrm{CO}}\right)$ & $1.610^{-17 c, e}$ & $<6.110^{15}$ \\
\hline 1713 (IV) & 1676 & $\mathrm{CH}_{3} \mathrm{OCHO}^{\diamond}\left(v_{\mathrm{CO}}\right)$ & $4.810^{-17 i}$ & $4.610^{14}$ \\
\hline $1709(\mathrm{~V})$ & 1669 & $\mathrm{HOCH}_{2} \mathrm{CHO}^{\diamond}\left(2 v_{6}\right)$ & $210^{-17} b, j$ & \\
\hline 1697 (VI) & 1655 & $\mathrm{HCOOH}^{\diamond}\left(v_{\mathrm{CO}}\right)$ & $5.410^{-17} a, d$ & $1.510^{15}$ \\
\hline 1496 & 1497 & $\mathrm{H}_{2} \mathrm{CO}^{\diamond}\left(\delta_{C H}\right)$ & $5.110^{-18 c}$ & \\
\hline 1459 & 1058 & $\mathrm{CH}_{3} \mathrm{OH} \quad\left(\delta_{C H}\right)$ & $6.510^{-18 c}$ & \\
\hline 1374 & 1372 & $\mathrm{HOCH}_{2} \mathrm{CHO}^{\diamond} \quad\left(\delta_{\mathrm{CH}}\right)$ & $7.710^{-18 c}$ & \\
\hline 1129 & 1124 & $\mathrm{CH}_{3} \mathrm{OH} \quad\left(\rho_{\mathrm{CH}}\right)$ & $1.410^{-18 a}$ & $1.810^{16}$ \\
\hline 1107 & - & $\mathrm{HOCH}_{2} \mathrm{CHO}^{\diamond}\left(\rho_{\mathrm{CH}}\right)$ & $8.110^{-18 c, k}$ & \\
\hline 1020 & 1012 & $\mathrm{CH}_{3} \mathrm{OH} \quad\left(v_{\mathrm{CO}}\right)$ & $1.810^{-17 a}$ & \\
\hline
\end{tabular}

Notes: the numbers in parentheses are the deconvoluted peak numbers as shown in Fig. $9 . v$ : stretching; $\delta$ : bending; $\rho$ : rocking; $\omega$ : wagging. ${ }^{\dagger}$ Tentatively assigned. ${ }^{\diamond}$ Confirmed by QMS-TPD (see section 3.5.2). ${ }^{\ddagger}$ Column density of acetic acid assuming it is the only carrier of the band located at $1770 \mathrm{~cm}^{-1}$.

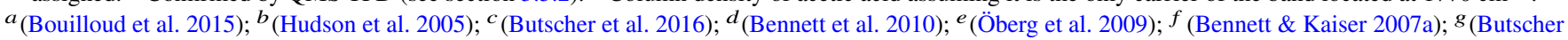
et al. 2017); ${ }^{i}$ (Modica \& Palumbo 2010); ${ }^{j}$ (Maity et al. 2015); ${ }^{k}$ (Butscher et al. 2015).

Table 5. Possibly formed molecules during matrix desorption, considering all detected radicals after VUV photolysis of $\mathrm{CH}_{3} \mathrm{OH} / \mathrm{Ar}$ samples. Species are highlighted in different colors: green $=$ detected only after the rare gas desorption, cyan $=$ detected during VUV photolysis, red $=$ not detected and yellow $=$ we cannot conclude.

\begin{tabular}{|c|c|c|c|c|c|c|c|}
\hline & $\mathrm{H}^{\bullet}$ & ${ }^{\circ} \mathrm{OH}$ & $\mathrm{H}^{*} \mathrm{CO}$ & ${ }^{\circ} \mathrm{CH}_{3}$ & ${ }^{\circ} \mathrm{CH}_{2} \mathrm{OH}$ & $\mathrm{CH}_{3} \mathrm{O}^{-}$ & $\mathrm{HO}^{*} \mathrm{CO}$ \\
\hline $\mathrm{H}^{\bullet}$ & \multirow[t]{7}{*}{ Dihydrogen } & Water & Formaldehyde & Methane & Methanol & Methanol & Formic acid \\
\hline${ }^{\circ} \mathrm{OH}$ & & \multirow[t]{6}{*}{ H-peroxide } & \multirow{6}{*}{$\begin{array}{c}\text { Formic acid } \\
\text { Glyoxal }\end{array}$} & Methanol & Methanediol & Methyl hydroperoxide & Carbonic acid \\
\hline $\mathrm{H}^{\bullet} \mathrm{CO}$ & & & & Acetaldehyde & \multirow{5}{*}{$\begin{array}{l}\text { Glycolaldehyde } \\
\text { Ethanol } \\
\text { Ethylene glycol }\end{array}$} & Methyl formate & \multirow{5}{*}{$\begin{array}{c}\text { Glyoxylic acid } \\
\text { Acetic acid } \\
\text { Glycolic acid } \\
\text { Methoxy formic acid } \\
\text { Oxalic acid }\end{array}$} \\
\hline${ }^{\circ} \mathrm{CH}_{3}$ & & & & Ethane & & Dimethyl ether & \\
\hline${ }^{\circ} \mathrm{CH}_{2} \mathrm{OH}$ & & & & & & Methoxymethanol & \\
\hline $\mathrm{CH}_{3} \mathrm{O}^{\bullet}$ & & & & & & Dimethyl peroxide & \\
\hline $\mathrm{HO}^{\circ} \mathrm{CO}$ & & & & & & & \\
\hline
\end{tabular}

C-H bending, C-H rocking, and C-O stretching modes of methanol, respectively (Table 4). Additional bands due to new species are also detected in the spectrum. $\mathrm{CO}_{2}$ is identified by its band at $2340 \mathrm{~cm}^{-1}$ (Table 4). Interestingly, the quantity of $\mathrm{CO}_{2}$ is comparable to that of other species after the Ar desorption (Table 4) while it was observed as trace after photolysis. This indicates a $\mathrm{CO}_{2}$ formation mechanism involving radicals during the $\mathrm{Ar}$ desorption, which will be discussed in section 4. Formaldehyde can be identified through its most intense peaks at 1726 and $1496 \mathrm{~cm}^{-1}$. One has to keep in mind that this product was already observed before the Ar desorption and does not belong necessary to radical recombination products.

However, assumptions of the species formed from radical-radical recombination can be made based on the radicals present before the rare gas desorption. Identified radical intermediates were $\mathrm{H}^{*} \mathrm{CO}$, $\mathrm{HO}^{\circ} \mathrm{CO},{ }^{\circ} \mathrm{CH}_{3},{ }^{\circ} \mathrm{OH},{ }^{\circ} \mathrm{CH}_{2} \mathrm{OH}$, and $\mathrm{CH}_{3} \mathrm{O}{ }^{\circ}$, we therefore expect to detect new stable products mainly coming from recombination of these radicals as shown in Table 5. Glycolaldehyde (GA) is easily identified by its $\mathrm{C}=\mathrm{O}$ stretching mode around $1750 \mathrm{~cm}^{-1}$ (Hudson et al. 2005; Bennett \& Kaiser 2007a,b). We were also able to detect the $\mathrm{CH}$ bending mode at $1374 \mathrm{~cm}^{-1}$ and the $\mathrm{CH}$ rocking mode at $1107 \mathrm{~cm}^{-1}$ (Fig. 8) which confirm its formation (Table 4). Since the methoxy radical $\mathrm{CH}_{3} \mathrm{O}^{\circ}$ was detected before the Ar matrix desorption, the formation of methyl formate (MF) is expected. Some infrared features observed in the solid film (Fig. 8) are consistent with the presence of methyl formate (Bennett \& Kaiser 2007a,b). However, the main difficulty lies in the fact that the strongest band from MF located at around $1713 \mathrm{~cm}^{-1}$ overlaps with the one from the dominant product, formaldehyde. Still, the new absorption features connected to the carbonyl group in the $1800-1600 \mathrm{~cm}^{-1}$ region are very broad and suggest more than one molecular carrier (Fig. 8). Therefore, we performed a deconvolution in this zone (Fig. 9). Six distinct bands are clearly identified centered at 1697, 1709, 1713, 1726, 1750, and $1770 \mathrm{~cm}^{-1}$ (Table 4). The bands at 1750 (II) and $1709(\mathrm{~V}) \mathrm{cm}^{-1}$ have been assigned to the $v_{14}$ and $2 v_{6}$ modes of GA (Hudson et al. 2005; Maity et al. 2015). The band at 1726 (III) $\mathrm{cm}^{-1}$ is assigned to $v_{4}$ mode of $\mathrm{H}_{2} \mathrm{CO}$ (Butscher et al. 2016) although con- 


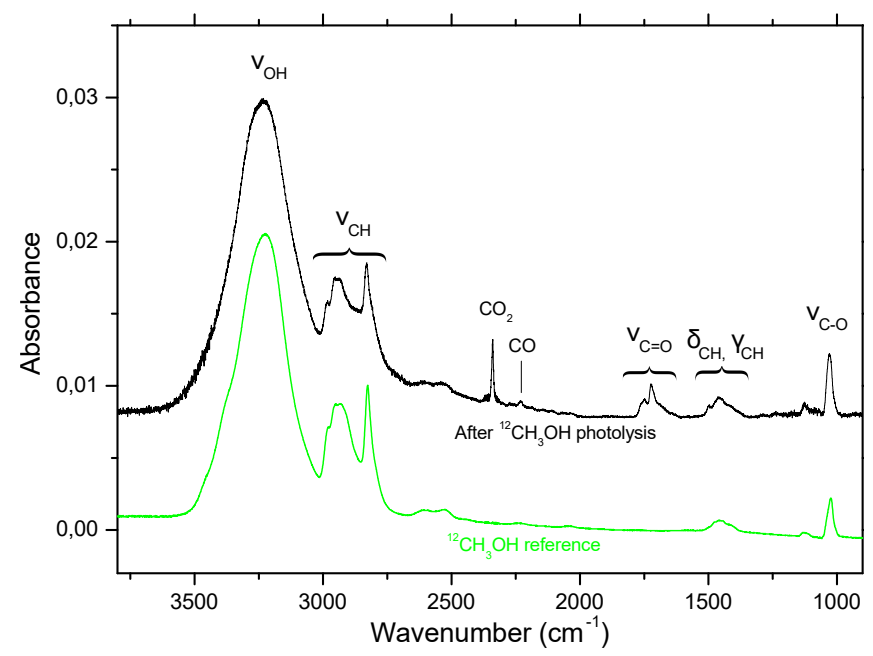

Figure 8. IR spectrum of the solid film recorded at $40 \mathrm{~K}$ after rare gas desorption of the photolysed ${ }^{12} \mathrm{C}$ methanol sample.

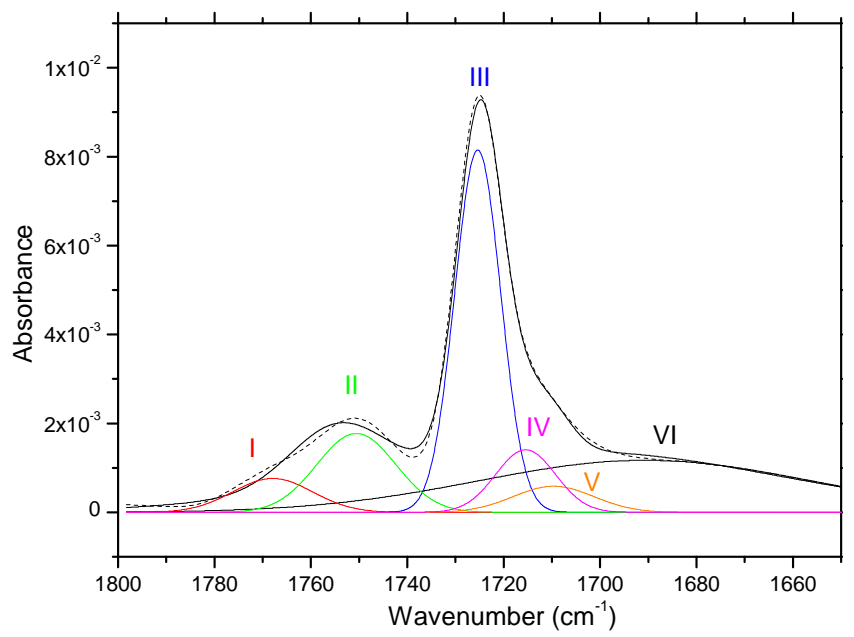

Figure 9. Deconvoluted infrared absorption features in the region of the carbonyl functional group in solid films recorded at $40 \mathrm{~K}$ obtained after sublimation of the photolysed $\mathrm{CH}_{3} \mathrm{OH} / \mathrm{Ar}$. The numbers in parentheses are the deconvoluted peak numbers: (I) Acetic acid (tentatively); (II) Glycolaldehyde; (III) Formaldehyde; (IV) Methyl formate; (V) Glycolaldehyde; (VI) Formic Acid. The presence of species (II)-(VI) was confirmed by QMS-TPD. We cannot discard the presence of glyoxal, that can be hidden under the most intense formaldehyde band.

tribution of glyoxal in this feature cannot be excluded (Öberg et al. 2009; Butscher et al. 2017). The one at 1713 (IV) $\mathrm{cm}^{-1}$ is assigned to the $v_{14}$ mode of MF (Maity et al. 2015). The broad band at 1697 (VI) $\mathrm{cm}^{-1}$ is assigned to the $v_{3}$ mode of formic acid (Bennett et al. 2010). Finally, the one located at 1770 (I) $\mathrm{cm}^{-1}$ can be due to carboxylic acid or related compounds and is tentatively assigned to the $v_{4}$ of acetic acid (Bennett \& Kaiser 2007a; Öberg et al. 2009).

Nonetheless, the infrared spectrum of the solid sample is not sufficient to distinguish all species formed; another technique has to be used.

\subsubsection{QMS-TPD of volatile species}

Quadrupole mass spectrometry was used during the TPD step in order to confirm or disprove our previous assignments. This technique provides important information about the final stable products as each species has a characteristic desorption temperature. Once this temperature is reached, the gas-phase compound can be analysed by mass spectrometry through a fragmentation pattern that is also characteristic of the species structure. The evolution of the ionic current intensity versus the sample temperature is displayed in Fig. 10 for ${ }^{12} \mathrm{C}$ (left panel) and ${ }^{13} \mathrm{C}$ (right panel). The analysis of the TPD signals allows us to confirm the previous assignments made by FT-IR spectroscopy and to identify five additional compounds (see Fig. 11). Several of the expected products (see Table 5) cannot be clearly identified or are not formed at all.

3.5.2.1 Securely identified molecules. Molecules that have been certainly assigned by mass spectrometry and/or infrared spectroscopy after VUV photolysis and argon desorption (i.e. in the solid film) are highlighted in blue and green in Table 5 and are described next.

Dimethyl ether $\mathrm{CH}_{3} \mathrm{OCH}_{3}$ (1) molecular ion $\mathrm{m} / \mathrm{z}=46 \mathrm{amu}$ ) is reported to desorb as a pure fraction between 80 and $90 \mathrm{~K}$ (Öberg et al. 2009). In our experiments, the desorption of the characteristic DME fragments $\mathrm{m} / z=45$ and $\mathrm{m} / z=46$ (see NIST database) occurs around $80 \mathrm{~K}$ (Left panel of Fig. 10). The intensity ratio of $\mathrm{m} / z=45$ over $m / z=46$ is about two as reported in the NIST database. In the ${ }^{13} \mathrm{C}$ experiment, the $m / z=47$ fragment is also observed at the same temperature as in the ${ }^{12} \mathrm{C}$ experiment. There is no evidence of the $m / z=48$ fragment belonging to ${ }^{13} \mathrm{C}$ dimethyl ether, which can be attributed to a lower amount of produced DME and the non perfect baseline.

Formaldehyde $\mathrm{H}_{2} \mathrm{CO}$ (2) molecular ion $\mathrm{m} / \mathrm{z}=30 \mathrm{amu}$ ) is clearly seen with the infrared spectroscopy and is known to desorb around $100 \mathrm{~K}$ (Chuang et al. 2016). There is no doubt of its desorption at this temperature in our experiments as $m / z=30$ and $m / z=31$ are detected in ${ }^{12} \mathrm{C}$ and ${ }^{13} \mathrm{C}$ respectively.

Ethanol $\mathrm{CH}_{3} \mathrm{CH}_{2} \mathrm{OH}$ (3) molecular ion $\mathrm{m} / \mathrm{z}=46 \mathrm{amu}$ ) is reported to desorb in the 130-140 K range (Öberg et al. 2009). When ionized using $70 \mathrm{eV}$ electrons, ethanol gives $\mathrm{m} / \mathrm{z}=46$ and $\mathrm{m} / \mathrm{z}=45$ with a ratio $46 / 45$ of about 0.4 , close to the value obtained from MS spectrum in NIST database (0.42). In our experiments we observed a desorption around $118 \mathrm{~K}$ for both ${ }^{12} \mathrm{C}$ and ${ }^{13} \mathrm{C}(\mathrm{m} / \mathrm{z}=47$ and $\mathrm{m} / \mathrm{z}=48$ ) isotopologues. This is more than $10 \mathrm{~K}$ earlier than what is observed for pure ethanol which could be explained by its low quantity and its possible interaction with other species.

Methyl formate $\mathrm{CH}_{3} \mathrm{OCHO}$ (4) molecular ion $\mathrm{m} / \mathrm{z}=60 \mathrm{amu}$ ) is reported to desorb between 100 and $120 \mathrm{~K}$ when deposited in a pure fraction (Burke et al. 2015). This value depends on MF distribution (e.g. monolayers or multilayers) and can also be affected by the environment, finding even higher desorption temperatures when mixed or deposited onto water surface (Burke et al. 2014). Our own TPD of pure MF gives a desorption at $138 \mathrm{~K}$. These two references are consistent with the $\mathrm{m} / z=60$ and $\mathrm{m} / \mathrm{z}=62$ fragments desorbing around $120 \mathrm{~K}$ in ${ }^{12} \mathrm{C}$ and ${ }^{13} \mathrm{C}$ experiments respectively.

Glyoxal CHOCHO (5) molecular ion $\mathrm{m} / \mathrm{z}=58 \mathrm{amu}$ ) is a (very) minor product of HCO dimerization but is detectable from VUV irradiated ice analogue experiments (Butscher et al. 2017). The TPD of pure glyoxal made with our experimental setup gave a desorption temperature ranging from 140 to $160 \mathrm{~K}$. This is consistent with the $\mathrm{m} / \mathrm{z}=58$ and $\mathrm{m} / \mathrm{z}=60$ fragments desorbing between $135 \mathrm{~K}$ and 140 $\mathrm{K}$ in ${ }^{12} \mathrm{C}$ and ${ }^{13} \mathrm{C}$ experiments respectively.

Methanol $\mathrm{CH}_{3} \mathrm{OH}$ (6) molecular ion $\mathrm{m} / \mathrm{z}=32 \mathrm{amu}$ ) is the major species in our experiments as it is the chosen precursor. A very clear and intense signal is observed around $140 \mathrm{~K}$ for the $\mathrm{m} / \mathrm{z}=32\left({ }^{12} \mathrm{C}\right)$ and $m / z=33\left({ }^{13} \mathrm{C}\right)$ fragments on Fig. 10 . The $\mathrm{m} / z=30\left({ }^{12} \mathrm{C}\right)$ and $\mathrm{m} / \mathrm{z}=$ 

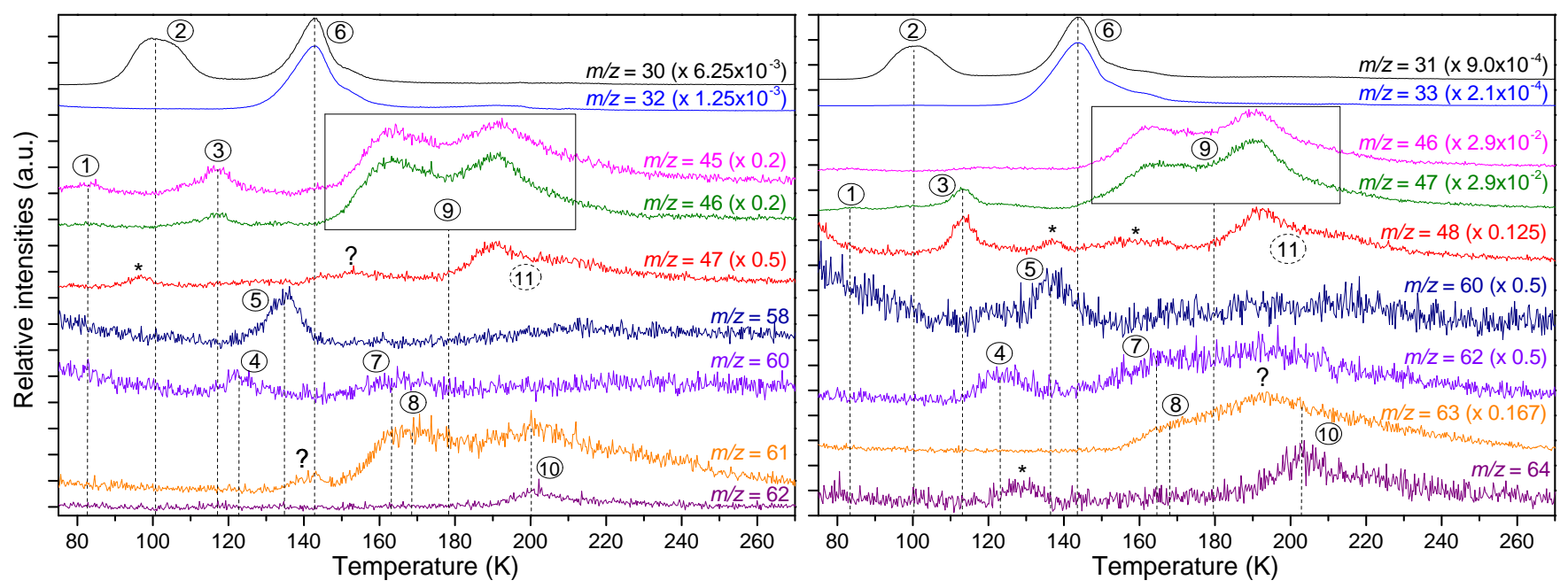

Figure 10. TPD traces $\left(4 \mathrm{~K} \cdot \mathrm{min}^{-1}\right.$ ) from the ${ }^{12} \mathrm{CH}_{3} \mathrm{OH} / \mathrm{Ar}$ (left panel) and the ${ }^{13} \mathrm{CH}_{3} \mathrm{OH} / \mathrm{Ar}$ (right panel) experiments. The characteristic molecular fragments of 10 identified species are displayed between 75 and $270 \mathrm{~K}$, and each desorption peak has been numbered from 1 to 10 corresponding to species in Fig. 11 . For clarity reasons, all signals are scaled in order to be in the same intensity range as the less intense one; scaling factors are shown in parentheses. The $11^{\text {th }}$ numbered species correspond to methanediol and/or methyl hydroperoxide (see section 3.5.2.3 for more information). Stars indicate that the observed patterns come from impurities also detected in the other isotopologue experiment with the same fragments. ? Unassigned.

\begin{tabular}{|c|c|c|}
\hline (1) Dimethyl ether & (2) Formaldehyde & (3) Ethanol \\
\hline $\mathrm{H}_{3} \mathrm{C}-\mathrm{O}-\mathrm{CH}_{3}$ & $\mathrm{H}_{2} \mathrm{C}=\mathrm{O}$ & $\mathrm{H}_{3} \mathrm{C}-\mathrm{CH}_{2}$ \\
\hline${ }^{12} \mathrm{C}: 46 \mathrm{amu}$ & ${ }^{12} \mathrm{C}: 30 \mathrm{amu}$ & ${ }^{12} \mathrm{C}: 46 \mathrm{amu}$ \\
\hline${ }^{13} \mathrm{C}: 48 \mathrm{amu}$ & ${ }^{13} \mathrm{C}: 31 \mathrm{amu}$ & ${ }^{13} \mathrm{C}: 48 \mathrm{amu}$ \\
\hline (4) Methyl formate & (5) Glyoxal & (6) Methanol \\
\hline$\stackrel{\mathrm{O}}{\mathrm{HC}}-\mathrm{O}-\mathrm{CH}_{3}$ & $\stackrel{\mathrm{O}}{\|} \stackrel{\mathrm{O}}{\| \mathrm{HC}}-\stackrel{\mathrm{CH}}{\|}$ & $\mathrm{H}_{3} \mathrm{C}-\mathrm{OH}$ \\
\hline${ }^{12} \mathrm{C}: 60 \mathrm{amu}$ & ${ }^{12} \mathrm{C}: 58 \mathrm{amu}$ & ${ }^{12} \mathrm{C}: 32 \mathrm{amu}$ \\
\hline${ }^{13} \mathrm{C}: 62 \mathrm{amu}$ & ${ }^{13} \mathrm{C}: 60 \mathrm{amu}$ & ${ }^{13} \mathrm{C}: 33 \mathrm{amu}$ \\
\hline
\end{tabular}

(7) Glycolaldehyde

(8) Methoxymethanol

(9) Formic acid

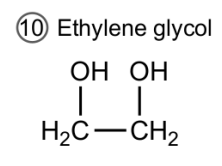<smiles>C1CCC1</smiles><smiles>COCO</smiles><smiles>O=CO</smiles>

${ }^{12} \mathrm{C}: 60 \mathrm{amu}$

${ }^{13} \mathrm{C}: 62 \mathrm{amu}$
${ }^{12} \mathrm{C}: 46 \mathrm{amu}$
${ }^{13} \mathrm{C}: 47$ amu

${ }^{12} \mathrm{C}: 62 \mathrm{amu}$

${ }^{13} \mathrm{C}: 64 \mathrm{amu}$

Figure 11. Structures of the ten numbered species whose desorptions are seen in Fig. 10. The mass of the molecular ${ }^{12} \mathrm{C}$ and ${ }^{13} \mathrm{C}$ ions are also displayed for a better understanding of Fig. 10 .

$31\left({ }^{13} \mathrm{C}\right)$ fragments (molecular fragments of formaldehyde) are also detected as these belong to the fragmentation pattern of methanol under 70-75 eV electrons (NIST database). However, the $\mathrm{m} / \mathrm{z}$ ratio $32 / 30$ is about 5 in our ${ }^{12} \mathrm{C}$ experiments while it is reported to be about 10 in the previously cited database. This is also corroborated in ${ }^{13} \mathrm{C}$ experiments from the $m / z=33$ over $m / z=31$ ratio. Such a difference might be explained by a possible co-desorption of formaldehyde trapped by methanol, as these two species are the most abundant in our experiments and must have good H-bond affinities. The $140 \mathrm{~K}$ desorption temperature is supported by one of our previous works where we reported the same desorption temperature for $\mathrm{MeOH}$ as a pure ice or when embedded in a complex mixture (Butscher et al. 2015).

Glycolaldehyde $\mathrm{HOCH}_{2} \mathrm{CHO}$ (7) molecular ion $\mathrm{m} / z=60 \mathrm{amu}$ ) is

reported to desorb between 140 and $150 \mathrm{~K}$ as a pure fraction (Öberg et al. 2009). In Butscher et al. (2015), we reported a much higher desorption temperature for pure $(170 \mathrm{~K})$ as well as embedded GA (190 $\mathrm{K})$. Here, we observe that the molecular fragment of glycolaldehyde desorbs between 150 and $180 \mathrm{~K}$ in both ${ }^{12} \mathrm{C}$ and ${ }^{13} \mathrm{C}$ experiments. In addition, IR spectroscopy confirms the formation of this species.

Methoxymethanol $\mathrm{CH}_{3} \mathrm{OCH}_{2} \mathrm{OH}$ (8) molecular ion $\mathrm{m} / \mathrm{z}=62$ amu) is reported to desorb around $170 \mathrm{~K}$ (Boamah et al. 2014; Maity et al. 2015; Zhu et al. 2019). According to Johnson \& Stanley (1991) and Maity et al. (2015), the characteristic fragment for the detection of this molecule is not the molecular ion but the $\mathrm{m} / \mathrm{z}=61$ ${ }^{12} \mathrm{C}$ ) corresponding to $\mathrm{m} / \mathrm{z}=63$ in the ${ }^{13} \mathrm{C}$ experiment. These two fragments are detected at the reported temperature as it can be seen in Fig. 10.

Formic acid $\mathrm{HCOOH}$ (9) molecular ion $\mathrm{m} / z=46 \mathrm{amu}$ ) is reported to desorb as a pure fraction through a two-band pattern at 130 and $160 \mathrm{~K}$ (Zheng et al. 2006; Öberg et al. 2009; Chaabouni et al. 2020). We observe this typical two-band desorption at 160 and $190 \mathrm{~K}$ for the $m / z=46$ (M) and $m / z=45(\mathrm{M}-1)$ fragments $\left({ }^{12} \mathrm{C}\right)$ and for the $\mathrm{m} / \mathrm{z}$ $=47(\mathrm{M})$ and $m / z=46(\mathrm{M}-1)$ fragments $\left({ }^{13} \mathrm{C}\right)$ with a ratio $\mathrm{M} /(\mathrm{M}-1)$ around $3 / 2$. This ratio is highly consistent with what is reported in the NIST database for formic acid (1.3). Molecular interactions might explained the late desorption in our experiments.

Ethylene glycol $\mathrm{HOCH}_{2} \mathrm{CH}_{2} \mathrm{OH}$ (10) molecular ion $\mathrm{m} / \mathrm{z}=62 \mathrm{amu}$ ) could be the last species to desorb in our experiments. We detect its characteristic fragment both in ${ }^{12} \mathrm{C}(\mathrm{m} / \mathrm{z}=62 \mathrm{amu})$ and ${ }^{13} \mathrm{C}(\mathrm{m} / \mathrm{z}=64$ amu) around $200 \mathrm{~K}$. Öberg et al. (2009) reported its desorption as a pure ice between 180 and $200 \mathrm{~K}$ and regarding our own EG reference showed in Butscher et al. (2015), we observed a desorption occurring between 200 and $240 \mathrm{~K}$. In this last reference, we also noted that EG can desorb between 180 and $220 \mathrm{~K}$ when embedded in a complex mixture.

3.5.2.2 Undetected molecules. Molecules that are certainly not observed are highlighted in red in Table 5 and are described next.

Acetaldehyde $\mathrm{CH}_{3} \mathrm{CHO}$ (molecular ion $\mathrm{m} / z=44 \mathrm{amu}$ ) is expected to desorb between 100 and $150 \mathrm{~K}$ (Öberg et al. 2009; Maity et al. 
2015). Its two more intense fragments are $\mathrm{m} / \mathrm{z}=29$ and $\mathrm{m} / \mathrm{z}=44$ (30 and 46 respectively in ${ }^{13} \mathrm{C}$ ). In the expected temperature range, the only characteristic fragment is the ${ }^{13} \mathrm{C} \mathrm{m} / z=46$. The $\mathrm{m} / \mathrm{z}=29 / 30$ $\left({ }^{12} \mathrm{C} /{ }^{13} \mathrm{C}\right)$ fragment is mainly coming from methanol, and the $\mathrm{m} / \mathrm{z}=$ 44 from atmospheric $\mathrm{CO}_{2}$. It appears that there is no detectable $\mathrm{m} / \mathrm{z}$, $=46$ signal before $140 \mathrm{~K}$ in the ${ }^{13} \mathrm{C}$ experiment (see right panel of Fig. 10) ruling out acetaldehyde formation.

Dimethyl peroxide $\mathrm{CH}_{3} \mathrm{OOCH}_{3}$ (molecular ion $\mathrm{m} / \mathrm{z}=62 \mathrm{amu}$ ) is an isomer of EG. It was reported to desorb at 115 and/or $146 \mathrm{~K}$ (Zhu et al. 2019). According to the NIST database, the three more intense fragments produced by electron ionization of dimethyl peroxide are $m / z=29,31$, and 62 with relative intensities of 100,97 , and 59 $\%$, respectively. Similarly to the case of acetaldehyde, $m / z=29$ and 31 fragments cannot be used in the range of temperature 100-150 $\mathrm{K}$ because of the dominant desorption of methanol. However, the $\mathrm{m} / \mathrm{z}=62\left({ }^{12} \mathrm{C}\right)$ and $64\left({ }^{13} \mathrm{C}\right)$ fragments can be used to characterize dimethyl peroxide in this temperature range. Left panel of Fig. 10 does not show any $\mathrm{m} / \mathrm{z}=62$ signal before the desorption of EG around $200 \mathrm{~K}$. In case of the right panel of Fig. 10, signal is observed between 120 and $140 \mathrm{~K}$ for the corresponding ${ }^{13} \mathrm{C}$ fragment $(\mathrm{m} / \mathrm{z}=$ $64 \mathrm{amu}$ ). It belongs to an impurity since the same signal for the $\mathrm{m} / \mathrm{z}$ $=64$ is also detected in the ${ }^{12} \mathrm{C}$ experiment (data not shown).

Carbonic acid $(\mathrm{OH})_{2} \mathrm{CO}$ (molecular ion $\mathrm{m} / \mathrm{z}=62 \mathrm{amu}$ ) has been previously observed when irradiating $\mathrm{CO}_{2} / \mathrm{H}_{2} \mathrm{O}$ ices with protons (Gerakines et al. 2000), electrons (Zheng \& Kaiser 2007), and through surface reactions of $\mathrm{CO}$ molecules with non-energetic hydroxyl ( ${ }^{\circ} \mathrm{OH}$ ) radicals (Oba et al. 2010). TPD experiments were only carried out in the last two cases, showing that this molecule desorbs in the $210-250 \mathrm{~K}$ temperature range through its molecular fragment. This molecule shares the same molecular mass as EG but the difference is that it bears only one carbon atom. As a result, its ${ }^{13} \mathrm{C}$ molecular fragment becomes $m / z=63$ when the ${ }^{13} \mathrm{C}$ molecular fragment of EG remains $m / z=64$. As we observe a perfect correlation between the $m / z=62\left({ }^{12} \mathrm{C}\right)$ and $m / z=64\left({ }^{13} \mathrm{C}\right)$ for the desorption of EG around $200 \mathrm{~K}$, we can securely state that no detectable amount of carbonic acid is formed in our experiments. Otherwise, we should have obtained an additional signal for the $m / z=62$ fragment compared to the $m / z=64$ fragment.

3.5.2.3 Unclear detection or non-detectable molecules. There are some molecules we cannot certainly assign or discard either because experimental conditions does not allow their detection (first group), there are ambiguities making their identification unclear (second group), or because there is no reference about their mass spectrum (third group).

In the first group we find dihydrogen and ethane.

Dihydrogen desorption temperature is quite below the desorption temperature of argon. The remaining dihydrogen molecules trapped inside the matrix, that have not escape during the annealing step, desorb when the matrix is totally evaporated.

Ethane $\left(\mathrm{CH}_{3}\right)_{2}$ desorption temperature is reported to be around $60 \mathrm{~K}$, and starting around $50 \mathrm{~K}$ (Öberg et al. 2009; Abplanalp et al. 2016). This temperature is too close to the desorption temperature of argon, which is still desorbing at temperatures near $45 \mathrm{~K}$. In the performed experiments the samples were heated at this temperature for a long period to eliminate all the argon from the matrix before TPD experiments. This implies that ethane could desorb during this process preventing its attribution.

The second group is the biggest one; it includes the two $\mathrm{CH}_{4} \mathrm{O}_{2}$ isomers methanediol and methyl hydroperoxide, $\mathrm{H}$-peroxide, and all the acids except for methoxy formic acid.

$\mathrm{CH}_{4} \mathrm{O}_{2}$ isomers: We pay a special attention to $\mathrm{CH}_{4} \mathrm{O}_{2}$ isomers (molecular ion $\mathrm{m} / z=48 \mathrm{amu}$ ) namely methanediol $\left(\mathrm{HOCH}_{2} \mathrm{OH}\right)$ and methyl hydroxyperoxide $\left(\mathrm{CH}_{3} \mathrm{OOH}\right)$. No clear signal for the $\mathrm{m} / \mathrm{z}$ $=48$ fragment is observed between 75 and $270 \mathrm{~K}$. Nevertheless, according to a previous study done by one of the present authors (Duvernay et al. 2014), the desorption of methanediol can be observed through the $\mathrm{m} / z=47$ fragment $\left(\mathrm{CH}_{3} \mathrm{O}_{2}^{+}\right)$around $200 \mathrm{~K}$. Fig. 10 shows this characteristic fragment as well as the corresponding ${ }^{13} \mathrm{C} \mathrm{m} / z=48$ fragment acquired during the ${ }^{13} \mathrm{C}$ experiment. A clear signal is observed in both experiments around $200 \mathrm{~K}$ confirming the $\mathrm{CH}_{3} \mathrm{O}_{2}^{+}$formula attribution as there is only $1 \mathrm{amu}$ difference between the ${ }^{12} \mathrm{C}$ and ${ }^{13} \mathrm{C}$ experiments. However, we cannot clearly conclude on the identity of the desorbing molecule. Bergantini et al. (2018) discussed the possibility of having only $\mathrm{CH}_{3} \mathrm{OOH}$ to desorb in this range of temperature as $\mathrm{HOCH}_{2} \mathrm{OH}$ should decompose before desorption to give water and formaldehyde. In Duvernay et al. (2014), it has been theoretically and experimentally shown that $\mathrm{HOCH}_{2} \mathrm{OH}$ is stable from low temperature to its desorption temperature that is around $200 \mathrm{~K}$. To our knowledge the fragmentation pattern of $\mathrm{CH}_{3} \mathrm{OOH}$ when ionized at $70 \mathrm{eV}$ has not been reported. As a result, there are two possibilities: either both $\mathrm{CH}_{4} \mathrm{O}_{2}$ isomers are formed or only one of them is present in the samples. The first possibility could be supported by the fact that we see two desorption contributions on the $m / z=47$ fragment $\left(m / z=48\right.$ in case of ${ }^{13} \mathrm{C}$, see Fig. 10). All these ambiguities prevent us to firmly assign the observed signals. Nevertheless, it is clear that at least one of the $\mathrm{CH}_{4} \mathrm{O}_{2}$ isomers is formed.

Acetic, glyoxylic, glycolic and oxalic acids: In the case of acids, the only one that is securely detected is FA. We also have some clues on the formation of AA. One IR deconvoluted band could be attributed to this molecule (band I, see Fig. 9) and its desorption could be hidden by the one of its securely identified isomer GA. Indeed, similarly to GA, AA can be detected using mass spectrometry only through the $m / z=60\left({ }^{12} \mathrm{C}\right)$ and $62\left({ }^{13} \mathrm{C}\right)$ fragments. As the desorption peaks are relatively large for these fragments (see Fig. 10), one can think that, in addition to GA, AA also desorbs around $160 \mathrm{~K}$. This is corroborated by Burke et al. (2014) who reported really close desorptions of pure GA $(150 \mathrm{~K})$ and AA $(155 \mathrm{~K})$ in their conditions. Regarding glycolic acid, none of its characteristic $\mathrm{m} / \mathrm{z}$ fragments (31 (100), 32 (32), and 29 (21), with the relative intensities in parentheses, see NIST database) can be used as they are all present in methanol, the most abundant species in our experiments. Glyoxylic and oxalic acids share the same fragments $(\mathrm{m} / \mathrm{z}=44$ and 46$)$ as formic acid with $46 / 45=0.44$ and 0.58 respectively. However, the $\mathrm{m} / z$ ratio $46 / 45$ $\left({ }^{12} \mathrm{C}\right)$ or $47 / 46\left({ }^{13} \mathrm{C}\right)$ is greater than 1 in our experiments as for formic acid (Fig. 10) indicating that if glyoxylic and oxalic acids are formed, it is in a low amount.

H-peroxide $\mathrm{HOOH}$ is reported to desorb around $170 \mathrm{~K}$ through the $m / z=34$ fragment (Zheng et al. 2007). We are not able to conclude on its formation as our two isotopic experiments $\left({ }^{12} \mathrm{C}\right.$ and $\left.{ }^{13} \mathrm{C}\right) \mathrm{do}$ not give the same results as it should, H-peroxide not bearing any carbon atom.

There is only one molecule in the third group, namely methoxy formic acid $\mathrm{CH}_{3} \mathrm{OCOOH}$. Although this molecule has already been observed with FT-IR spectroscopy in argon matrix (Reisenauer et al. 2014) no mass spectra or TPD profile has been reported. Thus, there is not enough information to analyse this molecule in our TPD experiments, and in consequence no conclusion can be drawn.

In summary, from all the detected radicals, twenty five recombination products may be formed (see Table 5). Four of them were already detected in the argon matrix after photolysis and thus cannot be counted as species coming from ground state radical reactivity: 
water, formaldehyde, methane, and methanol (highlighted in blue in Table 5). Eight were clearly identified after the argon desorption from FT-IR and/or mass spectrometries: formic acid, glyoxal, glycoladehyde, methyl formate, ethanol, dimethyl ether, ethylene glycol, and methoxymethanol (highlighted in green in Table 5). Three were clearly not detected: acetaldehyde, dimethyl peroxide, and carbonic acid (highlighted in red in Table 5). Finally, ten are likely to be formed but the lack of clear spectroscopic characterisation prevents us to firmly state on their formation: dihydrogen, H-peroxide, ethane, methanediol, methyl hydroperoxide, glyoxylic acid, acetic acid, glycolic acid, methoxy formic acid, and oxalic acid (highlighted in yellow in Table 5).

\section{DISCUSSION}

As we have seen, the photolysis of methanol in argon matrix leads to several radicals which can accept free $\mathrm{H}$-atoms during the annealing step and the matrix evaporation. Due to the desorption of the argon matrix, all species (mainly radicals) can meet and react together to yield a certain number of relatively complex organic molecules. Here, we discuss these different chemistry processes trying to draw the reaction scheme for the formation of the detected COMs.

\subsection{Photolysis of methanol in Ar}

There are no experimental studies addressing the primary products of methanol after Lyman- $\alpha$ photolysis in argon matrix. Nevertheless, considering previous theoretical and experimental studies of VUV photolysis in the gas phase at 121, 157 and $193 \mathrm{~nm}$ as well as in solid environments, five main channels can be expected (reactions 2, 3, 4, 5, and 6) (Harich et al. 1999; Cheng et al. 2001; Lucas et al. 2015; Kayanuma et al. 2019; Öberg et al. 2009; Paardekooper et al. 2016; Bennett et al. 2007; Gerakines et al. 1996; Schutte \& Gerakines 1995).

$$
\mathrm{CH}_{3} \mathrm{OH} \stackrel{h v}{\longrightarrow}\left\{\begin{array}{l}
{ }^{\circ} \mathrm{CH}_{3}+{ }^{\circ} \mathrm{OH} \\
{ }^{\circ} \mathrm{CH}_{2} \mathrm{OH}+\mathrm{H}^{\cdot} \\
\mathrm{CH}_{3} \mathrm{O}^{\cdot}+\mathrm{H}^{\cdot} \\
\mathrm{H}_{2} \mathrm{CO}+\mathrm{H}_{2} \\
\mathrm{CH}_{4}+\mathrm{O}
\end{array}\right.
$$

All these radicals are clearly observed in this work by using FT-IR and/or EPR spectroscopies, including the $\mathrm{CH}_{3} \mathrm{O}^{\bullet}$ radical which has been assigned for the first time with FT-IR in argon matrix. However, it does not mean that they are only formed from primary processes, but they can also be formed from secondary photolysis.

Besides radicals and formaldehyde, two closed-shell molecules are also detected after the photolysis namely carbon monoxide and carbon dioxide. The formation of $\mathrm{CO}$ can easily be explained by the photolysis of $\mathrm{H}^{\circ} \mathrm{CO}$, which is mainly obtained by photolysis of formaldehyde as shown in reaction 7 (Sodeau \& Lee 1981; Gerakines et al. 1996):

$\mathrm{H}_{2} \mathrm{CO} \stackrel{h v}{\longrightarrow} \mathrm{H}^{*} \mathrm{CO}+\mathrm{H}^{\cdot} \stackrel{h v}{\longrightarrow} \mathrm{CO}+2 \mathrm{H}^{\bullet}$

However, the origin of $\mathrm{CO}_{2}$ is less obvious to determine since several mechanisms are possible to explain its presence during the photolysis (Gerakines et al. 1996; Roser et al. 2001; Loeffler et al. 2005; Jamieson et al. 2006; Madzunkov et al. 2006; Watanabe et al. 2007; Bennett et al. 2009; Arasa et al. 2013). It has to be noted that $\mathrm{CO}_{2}$ is formed during photolysis in argon matrix at a very low amount, according to the reactions 8,9 , and 10 indicated below.

$\mathrm{CO}+\mathrm{O} \longrightarrow \mathrm{CO}_{2}$

$\mathrm{CO}+\mathrm{h} v \longrightarrow \mathrm{CO}^{*}$

$\mathrm{CO}+\mathrm{CO}^{*} \longrightarrow \mathrm{CO}_{2}+\mathrm{C}$

$\mathrm{CO}+{ }^{\circ} \mathrm{OH} \longrightarrow \mathrm{HO}^{*} \mathrm{CO}^{*} \longrightarrow \mathrm{CO}_{2}+\mathrm{H}^{*}$

All reactions need a partner $(\mathrm{O}$-atoms in reaction $8, \mathrm{CO}$ in reaction 9 , and ${ }^{\circ} \mathrm{OH}$ in reaction 10 ) to diffuse which is unlikely at $14 \mathrm{~K}$ in argon matrix (except for $\mathrm{H}$-atoms). In these conditions, the $\mathrm{CO}_{2}$ may come from the photolysis of methanol dimers that are observed even in our experiments at very low $\mathrm{MeOH}$ concentration.

Species formed during the photolysis step are isolated in different cages and cannot diffuse at low temperature as mentioned before. However, when the temperature of the sample is increased close to the argon desorption temperature (i.e. $30 \mathrm{~K}$ ), free $\mathrm{H}$-atoms (and $\mathrm{CO}$ ) begin to diffuse inside the matrix triggering hydrogenation reactions that produce new species.

\subsection{Hydrogenation reactions}

During warming at $30 \mathrm{~K}$, several hydrogenation processes occur and can be observed when the temperature is set back to $14 \mathrm{~K}$. First, all products coming from $\mathrm{MeOH}$ photolysis can be hydrogenated (reaction 1). The only difference is that the hydrogenation of formaldehyde yields exclusively ${ }^{\circ} \mathrm{CH}_{2} \mathrm{OH}$ while methanol photolysis can give $\mathrm{CH}_{3} \mathrm{O}^{\circ}$ as well (Butscher et al. 2015). Two new products can be obtained from the hydrogenation of ${ }^{\circ} \mathrm{CH}_{3}$ (reaction 11) and ${ }^{\circ} \mathrm{OH}$ (reaction 12):

$\cdot \mathrm{CH}_{3}+\mathrm{H}^{\cdot} \longrightarrow \mathrm{CH}_{4}$

$\cdot \mathrm{OH}+\mathrm{H}^{\cdot} \longrightarrow \mathrm{H}_{2} \mathrm{O}$

Unfortunately, these two products were already observed in the matrix before the annealing preventing us to conclude about their formation mechanisms.

As carbon dioxide is observed during the photolysis, its hydrogenation reaction can occur during the annealing as shown in reaction 13 (Bennett et al. 2010).

$\mathrm{CO}_{2}+\mathrm{H}^{\bullet} \longrightarrow \mathrm{HO}^{*} \mathrm{CO}$

This radical is clearly observed with EPR (before and after annealing) and tentatively in FT-IR (only after annealing), and might in principle recombine with atomic hydrogen to produce formic acid as shown in reaction 14 (Bennett et al. 2010):

$\mathrm{HO}^{\circ} \mathrm{CO}+\mathrm{H}^{\bullet} \longrightarrow \mathrm{HCOOH}$

However, $\mathrm{HCOOH}$ is not observed during the annealing due to the very low amount of $\mathrm{HO}^{\circ} \mathrm{CO}$ radical meaning this mechanism cannot 
explain the large amount of formic acid produced in our experiment after the Ar desorption. As reported by Bennett et al. (2010), the dominating pathway to formic acid $(\mathrm{HCOOH})$ was found to involve another radical-radical recombination and will be developed in the next section.

\subsection{Radical-radical recombination}

Regarding all detected radicals $\left(\mathrm{H}^{\bullet}, \mathrm{HC}^{\circ} \mathrm{O}, \mathrm{HO}^{\circ} \mathrm{CO},{ }^{\circ} \mathrm{CH}_{3},{ }^{\circ} \mathrm{OH}\right.$, $\cdot{ }^{\circ} \mathrm{CH}_{2} \mathrm{OH}$ and $\left.\mathrm{CH}_{3} \mathrm{O}^{\circ}\right)$ in the matrix using FT-IR and EPR spectroscopies, twenty five recombination products are expected. One has to keep in mind that before the desorption of argon, no COMs are detected (except for the methanol precursor), so that all formed COMs come from the ground-state reactivity between radicals with other radical or non radical species. Here, we discuss the reactions involving two radical recombinations. The radical recombination mechanism has been already studied with a similar methodology for some of the COMs obtained in this work, e.g. GA and EG (Butscher et al. 2015). In Table 5 all possible radical recombination products are presented as a function of the radicals detected before the sublimation of the matrix cages. A color code is used to differentiate the different species (see caption of Table 5).

All the species detected in our experiments using FT-IR spectroscopy and/or mass spectrometry (highlighted in green in Table 5) are fully consistent with radical recombination processes. In other words, we did not observe any species other than those listed in Table 5 corresponding to free-radical recombination products. However, we did not observe all of them.

One class of molecules, namely carboxylic acids, remains full of uncertainty. Only the simplest molecule from this class was clearly detected: formic acid. For all the others, either the lack of spectroscopic information prevented detection, or they were not formed in a sufficient quantity to untangle their desorption from that of formic acid. The fact that we clearly observe only formic acid (FA) could be explained by the existence of two different pathways for its formation. The first one, involving the $\mathrm{HO}^{\circ} \mathrm{CO}$ radical, is common to all acids (see the last column of Table 5). As discussed earlier, this route is not efficient under our experimental conditions because no FA can be detected after the annealing step. This should be due to the low quantity of $\mathrm{HO}^{\circ} \mathrm{CO}$ radical. The second formation route passes through the recombination of $\mathrm{H}^{\circ} \mathrm{CO}$ and ${ }^{\circ} \mathrm{OH}$ radicals and seems to be the major pathway forming FA (Bennett et al. 2010). As FA is the only acid to benefit from two different formation pathways including one without any $\mathrm{HO}^{\circ} \mathrm{CO}$ radical, it could justify why it is the only acid clearly observed.

Interestingly, among the expected products, acetaldehyde is missing. This product is supposed to be formed from $\mathrm{H}^{\circ} \mathrm{CO}$ and ${ }^{\circ} \mathrm{CH}_{3}$ radicals that are abundantly formed in our experiments (Maity et al. 2015). Most of the recombination products involving $\mathrm{H}^{*} \mathrm{CO}$ are observed, namely GA, MF, FA, and glyoxal. In addition, those involving $\cdot \mathrm{CH}_{3}$, namely ethanol and DME, are also detected, making the none formation of acetaldehyde even more surprising. Recent theoretical studies might give an explanation on this unexpected behavior (Lamberts et al. 2019; Enrique-Romero et al. 2020). These have shown that the reaction between $\mathrm{H}^{*} \mathrm{CO}$ and ${ }^{\circ} \mathrm{CH}_{3}$ does not necessary lead to acetaldehyde. Depending on the environment as well as on the orientation of the radical precursors, the $\mathrm{H}$-abstraction reaction may occur instead (reaction 15):

$$
\mathrm{H}^{\bullet} \mathrm{CO}+{ }^{\cdot} \mathrm{CH}_{3} \longrightarrow \mathrm{CO}+\mathrm{CH}_{4}
$$

Usually, $\mathrm{H}$-abstraction reactions between radical and non-radical (e.g. ${ }^{\bullet} \mathrm{OH}+\mathrm{CH}_{3} \mathrm{OH}$ ) do have significant activation barriers on its reaction path difficult to overcome at low temperature. However, it has been proven (experimentally and theoretically) that such reactions can occur very rapidly at low temperature by not going over the barrier but rather by tunneling (Sims 2013; Shannon et al. 2013). These results are interpreted by the formation of a hydrogen-bonded complex that is stable enough to efficiently undergo quantum-mechanical tunneling (Shannon et al. 2013).

In the specific case of $\mathrm{H}$-abstraction reactions between $\mathrm{H}^{*} \mathrm{CO}+$ ${ }^{\circ} \mathrm{CH}_{3}$ two stable products are formed $\left(\mathrm{CO}\right.$ and $\left.\mathrm{CH}_{4}\right)$ and a barrierless reaction is expected. This is supported by theoretical calculation that show this reaction is barrierless in the gas phase and has only a small barrier (between 1 and $4 \mathrm{~kJ} \mathrm{~mol}^{-1}$ depending on theoretical levels) in a water environment (Lamberts et al. 2019; Enrique-Romero et al. 2016, 2020).

However, when irradiation/photolysis of methanol is conduced in solid environment (pure methanol or water dominated ices) acetaldehyde is detected (Öberg et al. 2009; Boamah et al. 2014; Maity et al. 2015; Abou Mrad et al. 2016). One has to keep in mind that in these experimental conditions primary products coming from first generation of radicals can be also photolysed forming second generation products. For instance, this could be the case of acetaldehyde which could be produced from ethanol irradiation/photolysis. Additional works are needed to check this hypothesis.

Some of the previously mentioned species could also be formed through non radical-radical addition reactions, as discussed next.

\subsection{Possible non radical-radical addition reactions}

As the desorption of the argon matrix occurs at $35 \mathrm{~K}$, it may open other reaction routes with small barriers, namely reaction involving a radical species and an unsaturated molecule (mainly $\mathrm{CO}$ or $\mathrm{H}_{2} \mathrm{CO}$ ). An example of such a reaction is given by $\mathrm{CO}_{2}$ formation. Indeed, carbon dioxide is only observed as trace before Ar sublimation and become one of the dominant products after Ar removal. As previously mentioned (section 4.1), $\mathrm{CO}_{2}$ can be formed through reaction 10 , where the ${ }^{\circ} \mathrm{OH}$ can result either from $\mathrm{CH}_{3} \mathrm{OH}$ photodissociation or thermal hydrogenation of oxygen species (Watanabe et al. 2007; Ioppolo et al. 2011; Noble et al. 2011; Zins et al. 2011; Arasa et al. 2013). It is fully on track with our experiments since all the precursors were present before the Ar sublimation (i.e ${ }^{\circ} \mathrm{OH}$ and $\mathrm{CO}$ ). This route passes through one intermediate $\mathrm{HO}^{\circ} \mathrm{CO}$ that is vibrationally excited and dissociate into $\mathrm{CO}_{2}+\mathrm{H}^{\circ}$. Laboratory experiments have shown that this route is efficient below $20 \mathrm{~K}$ (Watanabe et al. 2007; Ioppolo et al. 2011; Noble et al. 2011; Zins et al. 2011; Arasa et al. 2013) although reaction 10 has calculated activation barriers ranging from 7 to $35 \mathrm{~kJ} \mathrm{~mol}^{-1}$ depending on the conformation of the $\mathrm{HO}^{\circ} \mathrm{CO}$ intermediate (Arasa et al. 2013).

Reaction between $\mathrm{H}^{*} \mathrm{CO}$ radical and formaldehyde has been shown to occur at low temperature $(35 \mathrm{~K})$ leading to formaldehyde polymers, viz. POM (Butscher et al. 2016, 2019).

Following the same scheme, at least two species could be formed through non radical-radical addition reactions which are GA (reaction 16) and EG (reaction 17):

$\mathrm{H}^{\bullet} \mathrm{CO}+\mathrm{H}_{2} \mathrm{CO} \rightarrow \mathrm{CHOCH}_{2} \mathrm{O}^{\cdot} \stackrel{H}{\rightarrow} \mathrm{CHOCH}_{2} \mathrm{OH}(G A)$

$\cdot \mathrm{CH}_{2} \mathrm{OH}+\mathrm{H}_{2} \mathrm{CO} \rightarrow \mathrm{HOCH}_{2} \mathrm{CH}_{2} \mathrm{O} \stackrel{\text { H }}{\longrightarrow}\left(\mathrm{CH}_{2} \mathrm{OH}\right)_{2}(E G)$

The activation barriers for the reactions 16 and 17 have been 
previously calculated at B3LYP/dev2-TZVP level of theory to be 20 and $8 \mathrm{~kJ} \mathrm{~mol}^{-1}$ respectively (Butscher et al. 2019). It has also been shown experimentally in Layssac et al. (2020) that reaction 16 is likely to occur when performed in water dominated environments at temperature around $50 \mathrm{~K}$. In the case of EG the experimental evidence supporting reaction 17 was less clear. Nevertheless, knowing that the calculated reaction barrier for the formation of EG is 2.5 times lower than for GA, reaction 17 could greatly participate in the formation of EG as well. It should be noted that with such barriers a classical thermal mechanism cannot explain these reactions at $35 \mathrm{~K}$, and two main hypotheses have been considered although not fully analyzed: (1) a heavy atom tunneling, and (2) a decrease of the barrier by a specific adduct formation. So far, there is no evidence these reactions occur at $10 \mathrm{~K}$. In any case, the experimental results (Butscher et al. 2019) indicate this kind of reactions deserves more attention and should not be totally neglected.

Results from this work give convincing arguments about iCOM formation on interstellar grains through radical-radical recombination but also nuance them. Radical-radical recombination does not always form iCOMs such as in the case of acetaldehyde. In addition, since the radical reactivity in our experiments occurs at $35 \mathrm{~K}$, low barrier reactions between unsaturated molecules and radicals cannot be excluded. Further works are needed to disentangle these two processes (barrierless and low barrier reactions) and to test if the addition reaction is possible at lower temperature (below $35 \mathrm{~K}$ ).

\subsection{Astrophysical implication}

Despite the harsh conditions of the interstellar medium several iCOMs have been detected in it, especially in star-forming regions. It is currently accepted - or should we say supposed - that they are mainly formed through radical reactivity on interstellar grains although new gas phase formation routes are mounting (Skouteris et al. 2018). Results reported here support iCOM formation on interstellar grains from radical-radical recombinations but also from low barrier radical-unsaturated molecule reactions. It does not mean that iCOMs are exclusively formed on grains but that probably both routes coexist. The relative contribution of gas phase versus grain formation may depend on physical conditions (temperature, density, UV flux, etc).

All the COMs detected in this work have been observed in the ISM (Snyder et al. 1969; Zuckerman et al. 1971; Snyder et al. 1974; Brown et al. 1975; Zuckerman et al. 1975; Hollis et al. 2000, 2002; McGuire et al. 2017) except for glyoxal whose most stable form has a $C_{2 h}$ symmetry, preventing its detection. As mentioned before, they are all proposed to be formed on interstellar grains through barrierless radical-radical recombinations (Garrod \& Herbst 2006; Bennett \& Kaiser 2007b; Woods et al. 2012; Butscher et al. 2015; Fedoseev et al. 2015; Chuang et al. 2016, 2017). Nevertheless, alternative gas phase routes have been recently proposed to explain interstellar abundances of GA, FA, and AA (Skouteris et al. 2018). The case of MF is also to be considered. Its formation from $\mathrm{H}^{*} \mathrm{CO}$ and $\mathrm{CH}_{3} \mathrm{O}{ }^{*}$ is now doubtless in solid environment. However, this pathway may not be the dominant one. Observed ratios involving MF and GA in the ISM (MF/GA 3.35.2 and 40-52 depending on the ISM region (Coutens et al. 2015)) are not well reproduced neither in this work $(\mathrm{MF} / \mathrm{GA}=0.3$, Table 4) nor in UV processing of $\mathrm{CO}: \mathrm{CH}_{3} \mathrm{OH}$ ice mixtures (Chuang et al. 2017). Typically, less MF is formed compared to GA in the solid state than observed in the gas phase of the ISM (Öberg et al. 2009; Chuang et al. 2017). This suggests that MF formation would require some additional gas-phase routes as already proposed by Balucani et al. (2015) and Chuang et al. (2017).
Regarding the undetected molecules in our experiments (Table 5), acetaldehyde is the only one that has been observed in the ISM (Gottlieb 1973). Its non detection in our experiments could imply that $\mathrm{H}^{*} \mathrm{CO}+{ }^{\circ} \mathrm{CH}_{3}$ recombination reaction may not be the major route for its formation in the ISM. This is supported by recent experimental and theoretical works suggesting that additional gas phase reactions and/or grain processes are needed to explain its abundance in star forming regions (Enrique-Romero et al. 2020; Martín-Doménech et al. 2020).

\section{CONCLUSIONS}

We report new experimental results on the VUV photolysis of methanol trapped in argon matrix. These results allowed us to analyze the relation between a complex mixture of radicals produced inside the matrix $\left(\mathrm{H}^{*} \mathrm{CO}, \mathrm{HO}^{\circ} \mathrm{CO},{ }^{\circ} \mathrm{CH}_{2} \mathrm{OH}, \mathrm{CH}_{3} \mathrm{O}^{\cdot},{ }^{\circ} \mathrm{OH},{ }^{\circ} \mathrm{CH}_{3}\right.$, and $\left.\mathrm{H}^{*}\right)$ and the observed stable products (COMs) that are formed after matrix desorption. This was possible thanks to a new methodology combining matrix isolation and FT-IR, EPR, and QMS-TPD techniques allowing - for the first time - a quite extensive detection of precursor, radicals and formed COMs under the same experimental conditions. Unlike other approaches mainly focused on the produced COMS, the current methodology is mainly designed for a good characterisation of the radicals. Besides, the use of matrix isolation constrains the formation of only first generation COMs, as observed in this study. This allows us to draw a direct link between formed COMs and the radicals present in the sample. The high sensitivity and selectivity of EPR spectroscopy clearly increased the confidence in assigning radical species, being crucial for the detection of some species $\left(\mathrm{HO}^{\circ} \mathrm{CO}\right.$ and ${ }^{\circ} \mathrm{CH}_{3}$ ) hardly observed with FT-IR.

At least nine recombination products were formed (and clearly detected) in the solid film after argon removal, namely methyl formate $\left(\mathrm{CH}_{3} \mathrm{OCHO}\right)$, glycolaldehyde $\left(\mathrm{HOCH}_{2} \mathrm{CHO}\right)$, ethylene glycol $\left(\mathrm{HOCH}_{2} \mathrm{CH}_{2} \mathrm{OH}\right)$, glyoxal $(\mathrm{CHOCHO})$, ethanol $\left(\mathrm{CH}_{3} \mathrm{CH}_{2} \mathrm{OH}\right)$, formic acid $(\mathrm{HCOOH})$, dimethyl ether $\left(\mathrm{CH}_{3} \mathrm{OCH}_{3}\right)$, methoxymethanol $\left(\mathrm{CH}_{3} \mathrm{OCH}_{2} \mathrm{OH}\right)$ and $\mathrm{CH}_{4} \mathrm{O}_{2}$ isomers (methanediol and/or methyl hydroperoxide). These molecules are fully consistent with the radicals detected and strongly support the solid state scenario of iCOM formation in interstellar ices based on ground state radical-radical recombination mechanisms. Although, non radicalradical mechanisms cannot be excluded for some species.

On the other hand, the fact that acetaldehyde is not formed in these experiments supports previous results suggesting that radical-radical recombinations do not always preferentially lead to iCOM formation, and other routes need to be taken into account.

Finally, the infrared signature of the $\mathrm{CH}_{3} \mathrm{O}^{-}$radical was detected for the first time in argon matrix. Contrary to para-hydrogen matrix, no conversion to the ${ }^{\circ} \mathrm{CH}_{2} \mathrm{OH}$ isomer was observed in argon, clearly suggesting an important role of the environment.

\section{ACKNOWLEDGEMENTS}

The project leading to this publication has received funding from Excellence Initiative of Aix-Marseille University - A*MIDEX, a French "Investissements d'Avenir programme". This work was supported by the Programme National "Physique et Chimie du Milieu Interstellaire" (PCMI) of CNRS/INSU with INC/INP co-funded by Commissariat à l'Energie Atomique (CEA) and Centre National d Etudes Spatiales (CNES). This work was further supported by the Agence Nationale de la recherche (ANR) SIRC project (Grant ANR- 
SPV202448 2020-2024) and by the Deutsche Forschungsgemeinschaft (DFG, German Research Foundation) under Germany's Excellence Strategy - EXC-2033 - Projektnummer 390677874 RESOLV.

\section{DATA AVAILABILITY}

The data underlying this article will be shared on reasonable request to the corresponding author.

\section{REFERENCES}

Abe H., Takeo H., Yamada K. M., 1999, Chemical Physics Letters, 311, 153 Abou Mrad N., Duvernay F., Chiavassa T., Danger G., 2016, Monthly Notices of the Royal Astronomical Society, 458, 1234

Abplanalp M. J., Gozem S., Krylov A. I., Shingledecker C. N., Herbst E., Kaiser R. I., 2016, Proceedings of the National Academy of Sciences, 113,7727

Adrian F. J., Cochran E. L., Bowers V. A., 1962, The Journal of Chemical Physics, 36, 1661

Arasa C., van Hemert M. C., van Dishoeck E. F., Kroes G.-J., 2013, The Journal of Physical Chemistry A, 117, 7064

Balucani N., Ceccarelli C., Taquet V., 2015, Monthly Notices of the Royal Astronomical Society: Letters, 449, L16

Barnes A. J., Hallam H. E., 1970, Trans. Faraday Soc., 66, 1920

Becke A. D., 1993, J. Chem. Phys., 98, 5648

Beltrán M. T., Codella C., Viti S., Neri R., Cesaroni R., 2008, The Astrophysical Journal Letters, 690, L93

Bennett C. J., Kaiser R. I., 2007a, The Astrophysical Journal, 660, 1289

Bennett C. J., Kaiser R. I., 2007b, The Astrophysical Journal, 661, 899

Bennett C. J., Chen S., Sun B., Chang A. H. H., Kaiser R. I., 2007, The Astrophysical Journal, 660, 1588

Bennett C. J., Jamieson C. S., Kaiser R. I., 2009, Physical Chemistry Chemical Physics, 11, 4210

Bennett C. J., Hama T., Kim Y. S., Kawasaki M., Kaiser R. I., 2010, The Astrophysical Journal, 727, 27

Bergantini A., Zhu C., Kaiser R. I., 2018, The Astrophysical Journal, 862, 140

Boamah M. D., et al., 2014, Faraday discussions, 168, 249

Bouilloud M., Fray N., Bénilan Y., Cottin H., Gazeau M.-C., Jolly A., 2015, Monthly Notices of the Royal Astronomical Society, 451, 2145

Brown R., Crofts J., Godfrey P., Gardner F., Robinson B., Whiteoak J., 1975, The Astrophysical Journal, 197, L29

Burke D. J., Puletti F., Brown W. A., Woods P. M., Viti S., Slater B., 2014, Monthly Notices of the Royal Astronomical Society, 447, 1444

Burke D. J., Puletti F., Woods P. M., Viti S., Slater B., Brown W. A., 2015, The Journal of Physical Chemistry A, 119, 6837

Butscher T., Duvernay F., Theule P., Danger G., Carissan Y., HagebaumReignier D., Chiavassa T., 2015, Monthly Notices of the Royal Astronomical Society, 453, 1587

Butscher T., Duvernay F., Danger G., Chiavassa T., 2016, Astronomy \& Astrophysics, 593, A60

Butscher T., Duvernay F., Rimola A., Segado-Centellas M., Chiavassa T., 2017, Physical Chemistry Chemical Physics, 19, 2857

Butscher T., Duvernay F., Danger G., Torro R., Lucas G., Carissan Y., Hagebaum-Reignier D., Chiavassa T., 2019, Monthly Notices of the Royal Astronomical Society, 486, 1953

Carmichael I., 1994, The Journal of Physical Chemistry, 98, 5896

Chaabouni H., Baouche S., Diana S., Minissale M., 2020, Astronomy \& Astrophysics, 636, A4

Chen Y.-J., Ciaravella A., Muñoz Caro G. M., Cecchi-Pestellini C., JiménezEscobar A., Juang K.-J., Yih T.-S., 2013, The Astrophysical Journal, 778, 162

Cheng B.-M., Liu C.-P., Lo W.-J., Lee Y.-P., 2001, Nuclear Instruments and Methods in Physics Research Section A: Accelerators, Spectrometers, Detectors and Associated Equipment, 467, 1461
Chiang S., Hsu Y., Lee Y., 1989, The Journal of Chemical Physics, 90, 81

Chuang K.-J., Fedoseev G., Ioppolo S., van Dishoeck E., Linnartz H., 2016, Monthly Notices of the Royal Astronomical Society, 455, 1702

Chuang K.-J., Fedoseev G., Qasim D., Ioppolo S., van Dishoeck E., Linnartz H., 2017, Monthly Notices of the Royal Astronomical Society, 467, 2552

Coussan S., Bouteiller Y., Loutellier A., Perchard J., Racine S., Peremans A., Zheng W., Tadjeddine A., 1997, Chemical Physics, 219, 221

Coutens A., Persson M. V., Jørgensen J. K., Wampfler S. F., Lykke J. M., 2015, Astronomy \& Astrophysics, 576, A5

Diem M., Lee E. K., 1979, Chemical Physics, 41, 373

Dmitriev Y., 2004, Physica B: Condensed Matter, 352, 383

Do N. H., Voglozin D., Cooper P. D., 2014, Monthly Notices of the Royal Astronomical Society, 443, 207

Duvernay F., Rimola A., Theule P., Danger G., Sanchez T., Chiavassa T., 2014, Physical Chemistry Chemical Physics, 16, 24200

Enrique-Romero J., Rimola A., Ceccarelli C., Balucani N., 2016, Monthly Notices of the Royal Astronomical Society: Letters, 459, L6

Enrique-Romero J., et al., 2020, Monthly Notices of the Royal Astronomical Society, 493, 2523

Fedoseev G., Cuppen H., Ioppolo S., Lamberts T., Linnartz H., 2015, Monthly Notices of the Royal Astronomical Society, 448, 1288

Foster S. C., Misra P., Lin T. Y. D., Damo C. P., Carter C. C., Miller T. A., 1988, The Journal of Physical Chemistry, 92, 5914

Frisch M. J., et al., 2016, Gaussian16 Revision C.01

Garrod R., Herbst E., 2006, Astronomy \& Astrophysics, 457, 927

Gerakines P., Schutte W., Ehrenfreund P., 1996, Astronomy and Astrophysics, 312,289

Gerakines P., Moore M. H., Hudson R. L., 2000, Astronomy and Astrophysics, 357, 793

Gerson F., Huber W., 2003, Electron Spin Resonance Spectroscopy of Organic Radicals. Wiley, doi:10.1002/3527601627

Gottlieb C. A., 1973, in Gordon M. A., Snyder L. E., eds, Molecules in the Galactic Environment. p. 181

Hama T., Ishizuka S., Yamazaki T., Kimura Y., Kouchi A., Watanabe N., Sugimoto T., Pirronello V., 2017, Physical Chemistry Chemical Physics, 19,17677

Harich S., Lin J., Lee Y., Yang X., 1999, The Journal of Physical Chemistry A, 103, 10324

Henderson B. L., Gudipati M. S., 2015, The Astrophysical Journal, 800, 66

Herbst E., Van Dishoeck E. F., 2009, Annual Review of Astronomy and Astrophysics, 47, 427

Herbst E., van Dishoeck E. F., 2009, Annual Review of Astronomy and Astrophysics, 47, 427

Hollis J. M., Lovas F. J., Jewell P. R., 2000, The Astrophysical Journal Letters, 540, L107

Hollis J. M., Lovas F. J., Jewell P. R., Coudert L., 2002, The Astrophysical Journal Letters, 571, L59

Horn A., Møllendal H., Sekiguchi O., Uggerud E., Roberts H., Herbst E., Viggiano A., Fridgen T. D., 2004, The Astrophysical Journal, 611, 605

Hudson R. L., Moore M. H., Cook A. M., 2005, Advances in Space Research, 36,184

Inoue G., Akimoto H., Okuda M., 1979, Chemical Physics Letters, 63, 213

Ioppolo S., Van Boheemen Y., Cuppen H., Van Dishoeck E., Linnartz H., 2011, Monthly Notices of the Royal Astronomical Society, 413, 2281

Irvine M., Mathieson J., Pullin A., 1982, Australian Journal of Chemistry, 35, 1971

Iwasaki M., Toriyama K., 1978, Journal of the American Chemical Society, 100, 1964

Jacox M. E., 1977, Journal of Molecular Spectroscopy, 66, 272

Jacox M. E., 1979, Chemical Physics, 42, 133

Jacox M. E., 1981, Chemical Physics, 59, 213

Jacox M. E., 1988, The Journal of chemical physics, 88, 4598

Jacox M. E., Milligan D. E., 1973, Journal of Molecular Spectroscopy, 47, 148

Jacox M. E., Rook F. L., 1982, The Journal of Physical Chemistry, 86, 2899

Jamieson C. S., Mebel A. M., Kaiser R. I., 2006, The Astrophysical Journal Supplement Series, 163, 184

Johnson R., Stanley A., 1991, Applied spectroscopy, 45, 218 
Kayanuma M., Shoji M., Furuya K., Aikawa Y., Umemura M., Shigeta Y., 2019, Chemical Physics Letters, 714, 137

Khoshkhoo H., Nixon E. R., 1973, Spectrochimica Acta Part A: Molecular Spectroscopy, 29, 603

Komaguchi K., Kumada T., Aratono Y., Miyazaki T., 1997, Chemical Physics Letters, 268, 493

Krusic P. J., Meakin P., Jesson J. P., 1971, The Journal of Physical Chemistry, 75,3438

Kunttu H., Seetula J., Räsänen M., Apkarian V., 1992, J. Chem. Phys., 96, 5630

Laas J. C., Garrod R. T., Herbst E., Weaver S. L. W., 2011, The Astrophysical Journal, 728, 71

Lamberts T., Markmeyer M. N., Kolb F. J., Kästner J., 2019, ACS Earth and Space Chemistry, 3, 958

Langford V. S., McKinley A. J., Quickenden T. I., 2000, Journal of the American Chemical Society, 122, 12859

Layssac Y., Gutiérrez-Quintanilla A., Chiavassa T., Duvernay F., 2020, Monthly Notices of the Royal Astronomical Society, 496, 5292

Lee Y.-F., Chou W.-T., Johnson B. A., Tabor D. P., Sibert E. L., Lee Y.-P., 2015, Journal of Molecular Spectroscopy, 310, 57

Leroi G. E., Ewing G. E., Pimentel G. C., 1964, The Journal of Chemical Physics, 40, 2298

Loeffler M., Baratta G., Palumbo M., Strazzulla G., Baragiola R., 2005, Astronomy \& Astrophysics, 435, 587

Lucas M., Liu Y., Bryant R., Minor J., Zhang J., 2015, Chemical Physics Letters, 619, 18

Madzunkov S., Shortt B., MacAskill J., Darrach M., Chutjian A., 2006, Physical Review A, 73, 020901

Maity S., Kaiser R. I., Jones B. M., 2015, Physical Chemistry Chemical Physics, 17, 3081

Mao S., Kevan L., 1974, Chemical Physics Letters, 24, 505

Martín-Doménech R., Öberg K. I., Rajappan M., 2020, The Astrophysical Journal, 894, 98

McGuire B. A., 2018, The Astrophysical Journal Supplement Series, 239, 17

McGuire B. A., et al., 2017, The Astrophysical Journal Letters, 851, L46

Milligan D. E., Jacox M. E., 1967, The Journal of Chemical Physics, 47, 5146

Milligan D. E., Jacox M. E., 1969, J. Chem. Phys., 51, 277

Misra P., Zhu X., Hsueh C.-Y., Halpern J. B., 1993, Chemical Physics, 178, 377

Modica P., Palumbo M. E., 2010, Astronomy and Astrophysics, 519, A22

Noble J. A., Dulieu F., Congiu E., Fraser H. J., 2011, The Astrophysical Journal, 735, 121

Oba Y., Watanabe N., Kouchi A., Hama T., Pirronello V., 2010, The Astrophysical Journal, 722, 1598

Öberg K. I., Garrod R. T., Van Dishoeck E. F., Linnartz H., 2009, Astronomy \& Astrophysics, 504, 891

Occhiogrosso A., Viti S., Modica P., Palumbo M. E., 2011, Monthly Notices of the Royal Astronomical Society, 418, 1923

Paardekooper D., Bossa J.-B., Linnartz H., 2016, Astronomy \& Astrophysics, 592, A67

Pettersson M., Khriachtchev L., Jolkkonen S., Räsänen M., 1999, The Journal of Physical Chemistry A, 103, 9154

Powers D. E., Hopkins J. B., Smalley R. E., 1981, The Journal of Physical Chemistry, 85, 2711

Reisenauer H. P., Wagner J. P., Schreiner P. R., 2014, Angewandte Chemie, 126,11960

Remijan A. J., Wyrowski F., Friedel D. N., Meier D. S., Snyder L. E., 2005, The Astrophysical Journal, 626, 233

Roser J. E., Vidali G., Manicò G., Pirronello V., 2001, The Astrophysical Journal Letters, 555, L61

Rubin R., Swenson Jr G., Benson R., Tigelaar H., Flygare W., 1971, The Astrophysical Journal, 169, L39

Saenko E. V., Feldman V. I., 2016, Physical Chemistry Chemical Physics, 18, 32503

Schneider H., et al., 2019, Monthly Notices of the Royal Astronomical Society: Letters, 485, L19

Schutte W., Gerakines P., 1995, Planetary and Space Science, 43, 1253

Sears T. J., Radford H., Moore M. A., 1993, The Journal of chemical physics,
98,6624

Shannon R. J., Blitz M. A., Goddard A., Heard D. E., 2013, Nature chemistry, 5,745

Siegel S., Baum L. H., Skolnik S., Flournoy J. M., 1960, The Journal of Chemical Physics, 32, 1249

Sims I. R., 2013, Nature chemistry, 5, 734

Skouteris D., Vazart F., Ceccarelli C., Balucani N., Puzzarini C., Barone V., 2017, Monthly Notices of the Royal Astronomical Society: Letters, 468, L1

Skouteris D., Balucani N., Ceccarelli C., Vazart F., Puzzarini C., Barone V., Codella C., Lefloch B., 2018, The Astrophysical Journal, 854, 135

Snelson A., 1970, The Journal of Physical Chemistry, 74, 537

Snyder L. E., Buhl D., Zuckerman B., Palmer P., 1969, Physical Review Letters, 22, 679

Snyder L., Buhl D., Schwartz P., Clark F., Johnson D., Lovas F., Giguere P., 1974, The Astrophysical Journal, 191, L79

Sodeau J. S., Lee E. K. C., 1981, Reviews of Chemical Intermediates, 4, 259

Stoll S., Schweiger A., 2006, Journal of magnetic resonance, 178, 42

Tielens A. G. G. M., 2005, The Physics and Chemistry of the Interstellar Medium. Cambridge University Press, doi:10.1017/CBO9780511819056

Toriyama K., Iwasaki M., 1979, Journal of the American Chemical Society, 101,2516

Tsegaw Y. A., Sander W., Kaiser R. I., 2016, The Journal of Physical Chemistry A, 120, 1577

Tseng S.-S., Chang S., 1975, Origins of Life, 6, 61

Walton J. C., 2012, Encyclopedia of Radicals in Chemistry, Biology and Materials, 1, 147

Wang T., Bowie J. H., 2012, Organic \& Biomolecular Chemistry, 10, 3219

Watanabe N., Mouri O., Nagaoka A., Chigai T., Kouchi A., Pirronello V., 2007, The Astrophysical Journal, 668, 1001

Weigend F., Ahlrichs R., 2005, Phys. Chem. Chem. Phys., 7, 3297

Woods P. M., Kelly G., Viti S., Slater B., Brown W. A., Puletti F., Burke D. J., Raza Z., 2012, The Astrophysical Journal, 750, 19

Woods P. M., Slater B., Raza Z., Viti S., Brown W. A., Burke D. J., 2013, The Astrophysical Journal, 777, 90

Yamada T., Komaguchi K., Shiotani M., Benetis N. P., Sørnes A. R., 1999, The Journal of Physical Chemistry A, 103, 4823

Zheng W., Kaiser R. I., 2007, Chemical Physics Letters, 450, 55

Zheng W., Jewitt D., Kaiser R. I., 2006, The Astrophysical Journal, 648, 753

Zheng W., Jewitt D., Kaiser R. I., 2007, Physical Chemistry Chemical Physics, 9, 2556

Zhitnikov R., Dmitriev Y. A., 2002, Astronomy \& Astrophysics, 386, 1129

Zhu C., Frigge R., Bergantini A., Fortenberry R. C., Kaiser R. I., 2019, The Astrophysical Journal, 881, 156

Zins E.-L., Joshi P. R., Krim L., 2011, The Astrophysical Journal, 738, 175

Zuckerman B., Ball J. A., Gottlieb C. A., 1971, The Astrophysical Journal, 163, L41

Zuckerman B., et al., 1975, The Astrophysical Journal, 196, L99

This paper has been typeset from a $\mathrm{T}_{\mathrm{E}} \mathrm{X} / \mathrm{LT}_{\mathrm{E}} \mathrm{X}$ file prepared by the author. 